\title{
Okul Müdürlerinin Görüşleri Doğrultusunda Türkiye'de Mahremiyet Eğitimi
}

\author{
Erol KOÇOĞLU* Yunus Emre AVCI**
}

• Geliş Tarihi: 06.07.2021 • Kabul Tarihi: 31.10.2021 • Çevrimiçi Yayın Tarihi: 31.10.2021

\section{$\ddot{\mathbf{O} z}$}

Günümüzde daha çok cinsel eğitim olarak ifade edilen mahremiyet eğitimi, bireyin kadın ya da erkek olarak, cinsiyetine ilişkin gereklilikleri ve sorumlulukları öğrenmesi için alması gereken eğitim olarak tanımlanabilir. Toplumun talep ettiği mahremiyet eğitimi; zaman, kültürel altyapı, aile, coğrafya gibi birçok değişkene göre farklılık gösterebilir. Bu araştırmada okul müdürlerinin görüşleri doğrultusunda, Türkiye'de mahremiyet eğitiminin değerlendirilmesi amaçlanmıştır. Çalışma gurubu basit seçkisiz örnekleme tekniğiyle belirlenmiş olup Türkiye'deki çeşitli devlet okullarında görev yapan 40 okul müdüründen oluşmaktadır. Bu çalışma, nitel araştırma yöntemlerinden fenomenolojik yaklaşıma göre desenlenmiştir. Araştırma verileri içerik analiz tekniğiyle analiz edilmiş ve tematik kodlar araştırmacılar tarafından oluşturulmuştur. Veri toplamak amacıyla, araştırmacılar tarafindan hazırlanmış yarı yapılandırılmış görüşme formu kullanılmıştır. Araştırma verileri, görüşme formunda yer alan sorular yoluyla okul müdürleriyle yapılan çevrimiçi mülakatlardan toplanmıştır. Çalışmada ulaşılan bulgular tablo ve şekillerle sunulmuştur. Yapılan çalışmada ulaşılan bulgulara bakıldığında, mahremiyet eğitiminin cinsel farkındalık temasıyla açıklanması, okullarda mahremiyet eğitiminin birey açısından güvenli bir yaşam olanağı sağlaması nedeniyle gerekli olması, bireysel farkındalığı arttırmak amacıyla okullarda mahremiyet eğitimine yönelik çalışmaların son yıllarda artarak devam etmesi gibi dikkat çekici birçok sonuca ulaşıldığı söylenebilir.

Anahtar sözcükler: Mahremiyet eğitimi, mahremiyet, bedensel farkındalık, okul müdürü, görüşme.

\section{Atıf:}

Koçoğlu, E., ve Avcı, Y.E. (2022). Okul müdürlerinin görüşleri doğrultusunda Türkiye'de mahremiyet eğitimi. Pamukkale Üniversitesi Eğitim Fakültesi Dergisi, 54, 385-409. doi:10.9779.pauefd. 963546

\footnotetext{
* Doç.Dr.., Malatya, Türkiye, ORCID: 0000-0003-4595-2892, erol.kocoglu@inonu.edu.tr

** Dr.Öğrt. Üyesi., Siirt, Türkiye, ORCID: 0000-0002-1361-1463, yunusavci027@hotmail.com.
} 


\section{Giriș}

Aile, geçmişten günümüze tüm dünya toplumlarının en temel birimidir. Bu nedenle aile, coğrafya, kültür, iklim, sosyo-kültürel ve ekonomik yapı nedeniyle esneklik gösterdiği söylenebilir. Bu esnekliğe bağlı olarak, herhangi bir ailenin bir üyesi olan insanoğlunun hayatına etkisinin doğmadan önce başladığı ve hayatının son noktasına kadar etkisini koruduğu söylenebilir. Aidiyet duygusuyla çocuğun bağlı olduğu aile, kendisini birçok yönde şekillendirebilir (Özaslan ve Gültekin Akduman, 2018). Çocuğun sosyal uyumunda aktif rol oynayarak onları sosyal hayata hazırlar ve sosyal hayatla bütünleşmesini sağlar. Sahiplenme duygusunun çocuk tarafından ilk kazanılan kurum veya ortam olan ailenin özellikleri, onun geçmiş ve gelecek bağlamında gelişimini birçok boyutta etkilediği söylenebilir. Bu boyutlar, duygusal, sosyo-kültürel boyut olarak sıralanabilir. Tarih boyunca bireyin içerisinde yaşadığı topluma ait maddi ve manevi değerlerin kapsamlı olarak aktarılmasında birincil kurum aile olduğundan, onun kişilik yapısının, davranışlarının ve tutumlarının oluşmasında ailenin yetiştirme tarzı ve tutumlarının önemli bir etkiye sahip olduğu söylenebilir (Jago, Davison, Brockman, Page, Thompson and Fox, 2011). Aile, çocuğun bilişsel, duygusal ve psikomotor gelişimi üzerinde etkili olduğu için bireyin mahremiyet (cinsellik) eğitimi konusunda farkındalık düzeyinin oluşmasında etkili olduğu ifade edilebilir. Bununla birlikte, mahremiyet (cinsellik) eğitimine ilişkin, bireyin merak ve öğrenme isteğini içeren soruların yanıt bulduğu ilk yerde ailedir. Bu nedenle mahremiyet eğitimi kavramının temel ilkelerinin ilk kez ailede tanıtıldığı söylenebilir.

Çalışmanın ana konusu olan mahremiyet eğitimi kavramına yönelik yapılan çalışmalar incelendiğinde, cinsellik eğitimi kavramının ön plana çıktığı söylenebilir. Cinsellik eğitimi kavramı genel olarak dünyada bireyin cinsel özelliklerine ilişkin farkındalık düzeyi olarak ifade edilse de, bu kavramın bilinen tanımdan daha fazla olduğu söylenebilir. Çünkü, cinsellik eğitimi bireyin bütüncül olarak bedensel organlarını tanıyıp işlevlerine ilişkin, toplumsal anlamda rol ve model olmayı içerisinde barındırmaktadır. Buradan hareketle, cinsellik eğitimi kavramının kültürel, dini ve ahlaki yansımalarını içeren mahremiyet eğitimi kavramı doğrultusunda bu çalışma gerçekleşmiştir. Mahremiyet eğitimi, din, ahlak ve kültürün belirlediği çerçevede çocuk ve ergenlere kendilerini veya karşı cinsin özelliklerini öğrenmeleri, cinsiyet rollerini anlamaları ve kabul etmeleri, cinsel ihtiyaçlarını karşılamaları için verilen eğitim olarak ifade edilebilir (Diler, 2015; Güneş, 2017). Diğer bir deyişle mahremiyet eğitimi, bireyin hem kendi özel alanını koruyabilmesi hem de başkalarının özel alanlarına saygı duyabilmesi için bireyin ilgi ve isteklerini dini, ahlaki 
veya daha kapsamlı olarak insani bir şekilde eğitmektir. Tanımların da işaret ettiği gibi mahremiyet, bireye ait olması ve özel olması gereken bir alanı ifade etmektedir (Güneş, 2017).

\section{Kuramsal Altyapı}

Geçmişten günümüze birey, yaşam sürecinde birçok toplumsal, kültürel, gelişimsel ve psikolojik sorunlarla mücadele etmek zorunda kalmıştır. Bu problemleri tespit etmek için insanın yer aldığg gelişim döneminin özellikleri hakkında ipucu verecek olan değerlerden nelerin benimsendiği ve bu değerlerden hangilerinin tehdide uğradığını belirleme çabası içerisine girdiği söylenebilir (Mills, 2001; Livberber Göçmen, 2018). Özellikle modern çağda bireyin, "ne yapmalıyım, nasıl davranmalıyım, nasıl biri olmalıyım, bu hayatı nasıl yaşamalıyım ve ben kimim?" gibi sorularla içerisinde bulunduğu dönemi sorgulamaya başlaması, yaşamsal sürecine ilişskin farkındalık düzeyinin artmasını sağlamıştır (Giddens, 2014; Livberber Göçmen, 2018). Bireyin özellikle günümüz dünyasında, bu soruların cevabını gözlem yolu başkalarının hayatına bakarak öğrenmesi, sağlam temellere dayalı bir mahremiyet eğitiminin kendisine ailede ya da okulöncesi dönemde verilmediğinin göstergesi olarak değerlendirilebilir.

Toplumun önemli sosyolojik kurumlardan birini oluşturan ailenin bireyin hayati tercihleri üzerinde belirleyici bir etki sağlayarak, insanın; fizyolojik, sosyolojik, psikolojik, ekonomik ve toplumsal yönlerden şekillenmesinde etkili olduğu söylenebilir (Şahin, 2003). $\mathrm{Bu}$ durum, ailenin, bireyin doğum öncesi gelişiminden yaşamının sonuna kadar ne kadar önemli bir yere sahip olduğunun kanıtı olarak ifade edilebilir (Jago ve diğerleri, 2011). Bireyin geçirdiği gelişim dönemlerine bakıldığında, aile kritik bir öneme sahiptir. Şöyle ki, bireyin kişiliğinin oluşumu ve davranışlarının şekillenmesi ilk olarak ailenin kontrolü altında gerçekleşir. Bireyin ilk olarak ailesiyle ilişki kurarak, aileden edindiği deneyimler aracılığıyla toplumsal ve duygusal gelişiminin temellerini attığı söylenebilir (Özaslan ve Gültekin Akduman, 2018). Bu temel sayesinde birey, sonraki gelişim dönemlerinin içerdiği özellikleri daha özgüvenli bir şekilde kazanabilir. Bu dönemlerden biri, bireyin en temel beceri ve alışkanlıklar kazandığı, ilk öğrenmeleri gerçekleştirdiği, kendisini aktarabildiği, bireysel kontrolünü sağlayabildiği, kendisinin sahip olduğu yeterliliklerin farkında olup başkalarının yeterliliklerine önem veren, çalışma konusu olan mahremiyet eğitiminin de verildiği okul öncesi dönemdir (Köksal Akyol, 2015; Özaslan ve Gültekin Akduman, 2018). Mahremiyet eğitimi açısından bakıldığında okulöncesi dönem kritik bir süreç oluşturmaktadır. 
Geleneksel dönemin sona erip modernleşmenin başlanmasıyla mahremiyet eğitimi önem kazanmıştır. Çünkü modernleşmeyle birlikte, toplumlar bireyin cinsel beden farkındalığını artıran cinsellik eğitimine daha çok önem verdikleri söylenebilir. Cinsellik eğitimine verilen bu önem, bireyin bedensel özelliklerini tanıyı bu özelliklerin sorumluluklarını yerine getirmeyi ön plana aldıkları ifade edilebilir (Yüksel, 2003). Bu eğitim, uluslararası camiada da modernleşme dönemiyle ortaya çıkmıştır. Dünya Cinsel Sağlık Derneğinin (World Association for Sexual Health) Cinsel Haklar Bildirgesi'nin 6. maddesinde bu eğitim hakkına vurgu yapılmaktadır. Bu bildirgede "her bireyin herhangi bir müdahaleye maruz kalmadan kendi cinselliği, cinsel kimliği, cinsel davranışları konusunda mahremiyet hakkına sahip olduğu” ifade edilmektedir. Bu hak kişiye dair, mahremiyet kavramıyla ilgili öznel içeriğin gizli tutulmasını içermektedir (World Association for Sexual Health, 1999). Bu durumun günüz dünyasında ihlal edildiği söylenebilir. Özellikle, sosyal ağ sitelerinin iletişim sürecinde bilinçsizce ve ahlaki kurallar dikkate alınmadan yoğun olarak kullanılması (Litt, 2013) ve bu durumun bireyin mahremiyet sınırını aşıp onu baskı altına alması sebebiyle, mahremiyet eğitimi çerçevesinde bireyin her anlamda korunup desteklenmesi gerektiği ifade edilebilir (Yüksel, 2003). Bu kuşatmanın, özellikle çocukların dijital platformlardan yararlanma ve onları kullanımı konusunda, ebeveynlerin planlı etkinlikler gerçekleştirmesini beraberinde getirdiği söylenebilir (Majedi, Ghazinour, Chinaei and Barker, 2009; Saeri, Ogilvie, La Macchia, Smith and Louis, 2014). Bu etkinlikler, çocukların mahremiyet ya da cinsellik konusunda güvenilir bir şekilde bilinçlenmesini sağlayan uygulamalar olarak ifade edilebilir (Yannacopoulos, 2008). Bu uygulamaları içerisinde barındıran mahremiyet eğitimi, doğrudan çocuğun iç dünyasını etkileyip kendisiyle birlikte oryantasyon problemi yaşamadığı çevresine katkı sağlayan, bir değer eğitimi olarak tanımlanabilir (Güneş, 2015; Özaslan ve Gültekin Akduman, 2018).

Bir değer eğitimi olarak tanımlanabilen mahremiyet eğitimi, günümüz dünyasında, dünyanın herhangi bir coğrafyasında gelişim dönemlerinin yeterliklerini sağlıklı bir şekilde edinen çocuğun, çevreden gelen tehditlere karşı kendisini savunabilmesi için, ebeveynlere ve çocuğun eğitimi üzerinde belirleyici etkiye sahip olan okul müdürlerine çok önemli sorumluklar yüklediği ifade edilebilir. Bu sorumlukların başında, mahremiyet eğitimi ve gerekliliklerin aktarılmasının geldiği söylenebilir. Temellerinin ailede atıldığı bu eğitimin, okul öncesi dönem başta olmak üzere diğer bütün eğitim kademlerinde yöntem veya teknik olarak aktarımının şekillenmesi, ailede anne ve babaların bu eğitimle çocuğu nasıl buluşturduklarına bağlıdır (Çakır, 2015). Yukarıda da ifade edildiği gibi okulöncesi, 
mahremiyet eğitimini kazandırmada kritik dönem olarak ifade edilebilir. Mahremiyet eğitiminin ve bu dönemin eğitim açısından önemi, Türkiye'de Aile ve Sosyal Politikalar Bakanlığı tarafindan hazırlanan mahremiyet eğitimine ilişkin raporda ifade edilmiştir (Eraslan, Ergüt, Uysal ve Bulut, 2017; Özaslan ve Gültekin Akduman, 2018).

Mahremiyet (cinsellik) eğitiminin önemi, çocuğun kişiliğine ve ruhuna doğrudan dokunan, hem çocuğu hem de çocuğun bağlı olduğu çevreyi aidiyet duygusuyla besleyen ve bu çevreye değer katan bir eğitim türü olarak ele alınmasına dayandırılabilir. Bu nedenle mahremiyet eğitiminin bu çalışmada ele alınarak çalışılması önemlidir. Türkiye'de Aile ve Sosyal Politikalar Bakanlığı tarafından hazırlanan raporda mahremiyet eğitimine verilen önem dikkate alınarak, yapılan bu çalışmada, okul müdürlerinin "mahremiyet eğitimini" nasıl algıladıkları ve bu konuda ne düşündüklerini tespit etmeyi amaçlayan çalışma gerçekleştirilmiştir. Bu amaç doğrultusunda çalışmada aşağıdaki araştırma problemleri belirlenmiştir:

- Okul müdürlerine göre mahremiyet eğitimi nedir?

- Okul müdürlerine göre mahremiyet eğitiminin içeriği nasıl olmalıdır?

- Okul müdürlerine göre mahremiyet eğitimi nasıl verilmelidir?

- Okul müdürlerine göre medya araçlarının mahremiyet eğitimi üzerinde nasıl etkileri bulunmaktadir?

\section{Yöntem}

Nitel araştırma yöntemiyle gerçekleştirilen bu araştırmada, etik kurul onay raporu alındıktan sonra yöntem kısmı birtakım alt başlıklardan oluşturulmuştur. Bu alt başlıklar, yöntem kısmında çalışma konusu doğrultusunda detaylandırılmıştır.

\section{Araştırmanın Modeli}

$\mathrm{Bu}$ çalışma nitel araştırma yöntemlerinden fenomenolojik yaklaşıma göre desenlenmiş bir araştırmadır. Nitel araştırma, araştırma verilerini elde etmek amacıyla birçok tekniğin (Gözlem, görüşme, doküman analizi vb.) kullanıldığı, araştırma konusuna ilişkin görüşlerin, algıların ve olayların var olan doğal ortamda, kapsayıcı şekilde ifade edilmesine yönelik yöntem olarak tanımlanabilir. Fenomenolojik yaklaşım ise bize tümüyle yabancı olmayan aynı zamanda da tam anlamını kavrayamadığımız olguları araştırmayı amaçlayan çalışmalar olarak ifade edilebilir (Yıldırım ve Şimşek, 2005). Birçok görevinin yanı sıra mahremiyet eğitimini değerlendirmek üzere okullarda eğitsel faaliyetleri yürütmek ve denetlemekle 
yükümlü olan okul müdürlerinin fikirlerine başvurmak ve derinlemesine bilgi edinmek amacıyla fenomenolojik tasarım tercih edilmiştir.

\section{Veri Toplama Aracı}

Mahremiyet eğitimi konusu altında hazırlanan bu araştırmanın verileri, yarı yapılandırılmış görüşme formu tekniğiyle elde edilmiştir. Araştırmacılar tarafından bu tekniğe uygun olarak hazırlanan görüşme formu soruları, çalışma grubundaki katılımcılara sorularak veriler elde edilmiştir. Araştırma verilerini elde etmede kullanılan bu teknikte, araştırmacı tarafindan çalışma grubu üyelerinden her birine sorulacak sorular alan uzmanlarından destek alınarak önceden hazırlandı. Hazırlanan bu sorular, belli bir plan dahilinde çalışma grubu üyelerine araştırmacı tarafından yöneltildi. Yapılan görüşmelerde, soruların yöneltildiği katılımcıların aynı cevapları vermemelerini sağlamak amacıyla ayrıntıya inebilmeleri sağlandı (Altunışık, Çoşkun, Yıldırım ve Bayraktaroğlu, 2001). Bu araştırmada kullanılan görüşme formu için ilgili literatür taranmış, yarı yapılandırılmış taslak görüşme formu hazırlanarak öncelikle okul müdürleriyle görüşülüp sorular üzerinde belirlenen düzeltmeler yapılmıştır. Daha sonra yarı yapılandırılmış görüşme formu alan uzmanlarına inceletilmiş ve forma son hali verilmiştir.

\section{Çalışma Grubu}

Araştırmanın çalışma gurubu 2019-2020 eğitim-öğretim yılında, Türkiye' de 7 il merkezinde (Malatya, Siirt, Aydın, Bartın, Konya, Mersin ve Sakarya) yer alan okulöncesi, ilkokul ve ortaokul ve lisede görev yapan 40 okul müdüründen oluşturmaktadır. Tablo 1'de araştırmaya katılan okul müdürlerinin kişisel özellikleri verilmiştir. Araştırmaya görüşleriyle katkı sağlayan çalışma grubu üyeleri, seçkisiz örnekleme yöntemlerinden basit seçkisiz örnekleme doğrultusunda seçilmiştir. Bu örnekleme sayesinde, araştırmaya görüşleriyle katkı sağlayan çalışma grubundaki katılımcılar, yansızlık ilkesiyle belirlenmiştir. Basit seçkisiz örnekleme yönteminde evrendeki tüm birimler, örneğe seçilmek için eşit ve bağımsız bir şansa sahiptir. Bununla birlikte seçkisiz örnekleme yöntemleri temsili sağlamada diğer örnekleme yöntemlerinden daha güçlü ve örneklemin evreni temsil etme gücü daha yüksektir (Özen ve Gül, 2007).

Tablo 1. Araştırmaya Katılan Okul Müdürlerinin Kişisel Özellikleri 
E.Koçoğlu ve Y.E., Avc1/ Pamukkale Üniversitesi Eğitim Fakültesi Dergisi, 54, 385-409, 2022

391

\begin{tabular}{|c|c|c|c|c|c|}
\hline Müdürler & $\begin{array}{l}\text { Cinsiye } \\
\mathrm{t}\end{array}$ & $\begin{array}{c}\text { Eğitim } \\
\text { Durumu }\end{array}$ & $\begin{array}{l}\text { Mesleki } \\
\text { Kıdem }\end{array}$ & $\begin{array}{r}\text { İdari } \\
\text { Kıdem }\end{array}$ & Yaş \\
\hline Müdür 1 (Md1) & Erkek & Lisans & 16 y1l ve üstü & $11-16$ y1l & $36-54$ \\
\hline Müdür 2 (Md2) & Erkek & Lisans & 6-10 y1l & $1-5$ y1l & 35 ve alt1 \\
\hline Müdür 3 (Md3) & Erkek & Lisans & $1-5$ y1l & $1-5 \mathrm{y} 1 \mathrm{l}$ & 35 ve alt 1 \\
\hline Müdür 4 (Md4) & Erkek & Lisansüstü & $1-5 \mathrm{y} 1 \mathrm{l}$ & $1-5 \mathrm{y} 1 \mathrm{l}$ & 35 ve alt1 \\
\hline Müdür 5 (Md5) & Erkek & Lisans & 6-10 y1l & $1-5$ y1l & 35 ve alt 1 \\
\hline Müdür 6 (Md6) & Erkek & Lisans & 6-10 y1l & $1-5 \mathrm{y} 1 \mathrm{l}$ & 35 ve alt1 \\
\hline Müdür 7 (Md7) & Erkek & Lisans & 6-10 y1l & 6-10 y1l & 35 ve alt 1 \\
\hline Müdür 8 (Md8) & Erkek & Lisans & $1-5$ y1l & $1-5$ y1l & 35 ve alt 1 \\
\hline Müdür 9 (Md9) & Erkek & Lisans & $1-5$ y1l & $1-5$ y1l & 35 ve alt1 \\
\hline Müdür 10 (Md10) & Erkek & Lisans & 6-10 y1l & $1-5$ y1l & 35 ve alt 1 \\
\hline Müdür 11 (Md11) & Kadın & Lisansüstü & $11-16 \mathrm{y} 11$ & $6-10$ y1l & $36-54$ \\
\hline Müdür 12 (Md12) & Erkek & Lisans & 6-10 y1l & $1-5$ y1l & 35 ve alt 1 \\
\hline Müdür 13 (Md13) & Erkek & Lisans & $6-10$ y1l & $1-5$ y1l & 35 ve alt1 \\
\hline Müdür 14 (Md14) & Erkek & Lisans & 16 y1l ve üstü & 16 y1l ve & $36-54$ \\
\hline Müdür 15 (Md15) & Erkek & Lisans & $11-16 \mathrm{y} 11$ & $6-10 \mathrm{y} 11$ & $36-54$ \\
\hline Müdür 16 (Md16) & Erkek & Lisans & $1-5$ y1l & $1-5$ y1l & 35 ve alt 1 \\
\hline Müdür 17 (Md17) & Erkek & Lisans & $1-5 \mathrm{y} 1 \mathrm{l}$ & $1-5 \mathrm{y} 1 \mathrm{l}$ & 35 ve alt 1 \\
\hline Müdür 18 (Md18) & Erkek & Lisans & $11-16$ y1l & $6-10 \mathrm{y} 11$ & $36-54$ \\
\hline Müdür 19 (Md19) & Erkek & Lisans & $6-10$ y1l & $1-5$ y1l & 35 ve alt 1 \\
\hline Müdür 20 (Md20) & Erkek & Lisans & $1-5$ y1l & $1-5$ y1l & 35 ve alt 1 \\
\hline Müdür 21 (Md21) & Erkek & Lisans & 6-10 y1l & $1-5$ y1l & $36-54$ \\
\hline Müdür 22 (Md22) & Erkek & Lisans & $6-10$ y1l & $1-5 \mathrm{y} 1 \mathrm{l}$ & 35 ve alt 1 \\
\hline Müdür 23 (Md23) & Erkek & Lisans & $6-10$ y1l & $1-5$ y1l & $36-54$ \\
\hline Müdür 24 (Md24) & Erkek & Lisans & $6-10$ y1l & $1-5$ y1l & $36-54$ \\
\hline Müdür 25 (Md25) & Erkek & Lisans & $1-5$ y1l & $1-5$ y1l & 35 ve alt1 \\
\hline Müdür 26 (Md26) & Kadın & Lisans & 6-10 y1l & $1-5 \mathrm{y} 1 \mathrm{l}$ & 35 ve alt1 \\
\hline Müdür 27 (Md27) & Erkek & Lisans & $1-5$ y1l & $1-5$ y1l & $36-54$ \\
\hline Müdür 28 (Md28) & Erkek & Lisans & $1-5$ y1l & $1-5$ y1l & 35 ve alt 1 \\
\hline Müdür 29 (Md29) & Kadın & Lisans & $1-5 \mathrm{y} 11$ & $1-5 \mathrm{y} 1 \mathrm{l}$ & 35 ve alt1 \\
\hline Müdür 30 (Md30) & Erkek & Lisans & $1-5$ y1l & $1-5$ y1l & $36-54$ \\
\hline Müdür 31 (Md31) & Kadın & Lisans & $1-5$ y1l & $1-5$ y1l & 35 ve alt 1 \\
\hline Müdür 32 (Md32) & Erkek & Lisans & $11-16$ y1l & $1-5$ y1l & 35 ve alt 1 \\
\hline Müdür 33 (Md33) & Kadın & Lisans & $1-5 \mathrm{y} 11$ & $1-5 \mathrm{y} 1 \mathrm{l}$ & $36-54$ \\
\hline Müdür 34 (Md34) & Kadın & Lisans & $1-5$ y1l & $1-5$ y1l & 35 ve alt 1 \\
\hline Müdür 35 (Md35) & Erkek & Lisans & $1-5$ y1l & $1-5$ y1l & $36-54$ \\
\hline Müdür 36 (Md36) & Erkek & Lisans & $1-5$ y1l & $1-5 \mathrm{y} 1 \mathrm{l}$ & $36-54$ \\
\hline Müdür 37 (Md37) & Kadın & Lisans & $11-16 \mathrm{y} 1 \mathrm{l}$ & $1-5 \mathrm{y} 1 \mathrm{l}$ & 35 ve alt 1 \\
\hline Müdür 38 (Md38) & Kadın & Lisans & $1-5$ y1l & $1-5$ y1l & 35 ve alt 1 \\
\hline Müdür 39 (Md39) & Erkek & Lisans & $1-5 \mathrm{y} 11$ & $1-5 \mathrm{y} 1 \mathrm{l}$ & $36-54$ \\
\hline Müdür 40 (Md40) & Erkek & Lisans & 16 y1l ve üstü & $6-10$ y1l & 35 ve alt1 \\
\hline
\end{tabular}




\section{Verilerin Toplanması ve Analizi}

Türkiye'de 7 il merkezinde (Malatya, Siirt, Aydın, Bartın, Konya, Mersin ve Sakarya) yer alan okulöncesi, ilkokul ve ortaokul ve lisede görev yapan 50 okul müdürüyle Google Meet üzerinden görüşme yapılarak araştırmaya yönelik görüşmelerin yapılması konusunda izlenecek yöntemler görüşüldü. Okul müdürleri için uygun olan zaman konuşulup anlaşıldıktan sonra online olarak birebir görüşmeler yapıldı. Görüşme esnasında verilen yanıtlar araştırmacılar tarafından görüşme formlarına kayıt edilmiştir. Bu görüşmelerden birkaç okul müdürünün verdiği cevaplar, araştırmacılar tarafından yetersiz bulunup çalışmaya dâhil edilmedi.

Okul müdürleriyle online yapılan yapılan görüşmelerde, araştırmacılarca kaydedilen veriler betimlenerek yorumlandı. Analizlerde "içerik analizi" süreci takip edildi (Yıldırım ve Şimşek, 2005). Verilerin belirgin özelliklerine göre kategorilere ayrılmış ve neden sonuç ilişkileri irdelenmeye çalış1lıp, okuyucunun rahatça görebileceği özet bilgilere ulaşılmaya çalışılmıştır. Örnek cümlelerde cümle sonuna düşüncenin kime ait olduğu kısaltılarak eklendi. (Örneğin Müdür 1= Md1 olarak ifadelerinin sonuna kodlanmıştır). Düşüncesine örnek verilen müdürlerin kişisel özelliklerine "Çalışma Grubu” başlığı altında yer alan tablodan bakılabilir (Tablo 1). Araştırmanın geçerliliğini arttırmak amacıyla araştırmacılar, okul müdürlerinin konuya ilişkin görüşleri alırken, onları yönlendirecek soru ve davranışlardan kaçınıp, sanal ortamdaki görüşmenin doğal bir parçasıymış objektif yaklaşım gösterdiler. Araştırmaya görüşleriyle katkı sağlayan çalışma grubu üyelerinin üç hafta arayla, görüşme formundaki sorulara benzer yanıtlar vermeleri, araştırmanın güvenirliği açısından oldukça önemli olduğu söylenebilir.

\section{Bulgular}

\section{Mahremiyet Kavramına İlişkin Durum}

Online görüşme esnasında okul müdürlerine yarı yapılandırılmış görüşme formunda yer alan “Mahremiyet denince ne anlıyorsunuz?” sorusu yöneltilmiştir. Müdürlerin cevapları temalar halinde şekil 1' de verilmiştir. Çalışma grubunu oluşturan okul müdürlerinin mahremiyet tanımına ilişkin çeşitli algılara sahip oldukları söylenebilir (şekil 1). Çalışmada tema şeklinde verilen bulgulara bakıldığında, okul müdürlerinin, mahremiyet kavramını daha çok kişiye özel olanlar ve cinsel eğitim kapsamında yer alan kavramlara değindikleri görülmektedir. Sepetçi (2017) ve Aydın Avşar'ın (2018) da belirttiği üzere, okul 
müdürlerinin kişiye özel olanlar temasında gizliliği ve görünmezliği daha ön plana çıkararak doğu toplumlarına uygun bir anlayış sergiledikleri ifade edilebilir. $\mathrm{Bu}$ durumun, cinsel eğitim olarak da adlandırılan mahremiyet eğitiminin temelinde yer alan mahremiyet kavramına yönelik eğitim yöneticilerinin algıları hakkında önemli ipuçları verdiği söylenebilir.

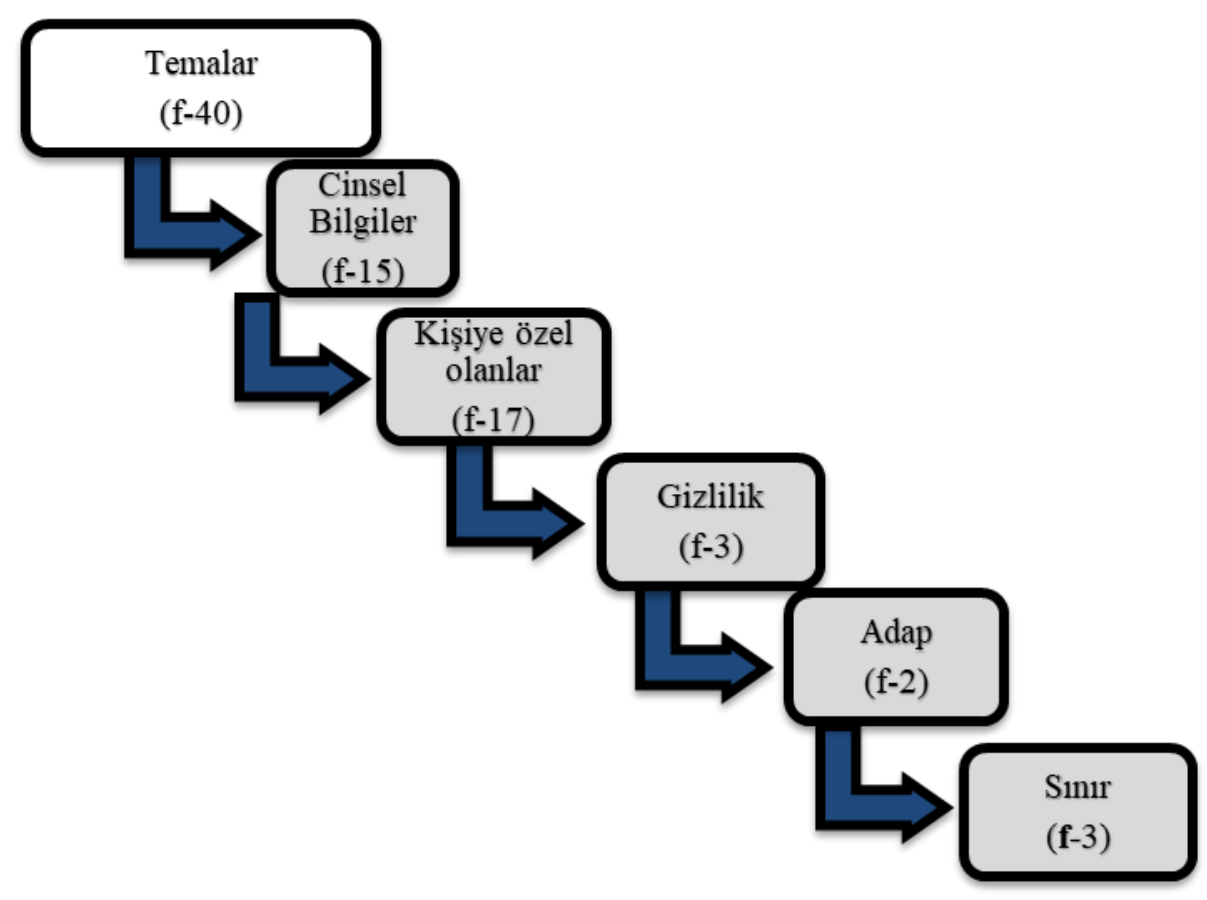

Şekil 1. Çalışma grubu üyelerinin mahremiyet kavramına ilişkin algıları

Kavramları ve olguları açıklayıcı bir cümleyle ifade etmek kolay olmadığından kavramsal açıklamalarda genel olarak, eş anlamlı olduğu düşünülen veya çağrışım yapan diğer kavramlarla ifade etme eğilimi görülmüştür. Okul müdürleri de mahremiyet kavramını açıklarken benzer olarak düşündükleri veya çağrışım yapan kavram ve olgulara çokça yer vermişlerdir. Müdürler mahremiyet kavramına yönelik yoğun olarak kişiye özel olan; bilgi, alan, özellikler gibi kavram ve olgulara değinmiştir. Daha sonra sırasıyla cinsel bilgilerin öğrenilmesi, gizliliğin sağlanması, adap olarak ifade edilen kurallar ve normların uygulanması ve sınırlara riayet edilmesi konularında fikir belirtmişlerdir. Mahremiyet kavramının tanımlanmasında cinsel bilgiler ve cinselliğe değinen okul müdürlerinin doğrudan ifadeleri şu şekildedir:

"Mahremiyet denilince cinsellik hakkında bilgiler aklıma geliyor. Genelde mahremiyet içerisinde cinsellik ve vücudun cinsiyete yönelik özelliklerinin bilinmesi bu kavram içinde yer alabilir" (Md4). Insanın mahrem sayılan cinsiyete yönelik bilgilere sahip olması ve korunmasıdır (Md15). Kendinin ve başkalarının özel alanlarının 
farkina varmak, içtimai hayatta başkalarının özeline saygı duymak, kendi özelini korumak ve sosyal ilişkilerde dinen ve örfen sağllkl sinırlar koymak mahremiyettir (M18). Kişinin kendisinin ve diğer insanların özel alaninın farkina varmast, sosyal hayat içinde kendi özel alanını koruması ve diğer insanların özeline saygı duymasıdır (Md23).

\section{Mahremiyet Eğitiminin Gerekliliğine İlişkin Durum}

Yarı yapılandırılmış görüşme formunda yer alan "Okullarda mahremiyet eğitiminin gerekli olduğunu düşünüyor musunuz, niçin?” sorusu görüşmede okul müdürlerine yöneltilmiş ve müdürler yanıtları "Evet" ve "Hayır" şeklinde iki tema olarak sunulmuştur. Temalar ve alt temalar gerekçeleriyle birlikte şekil 2'de verilmiştir.
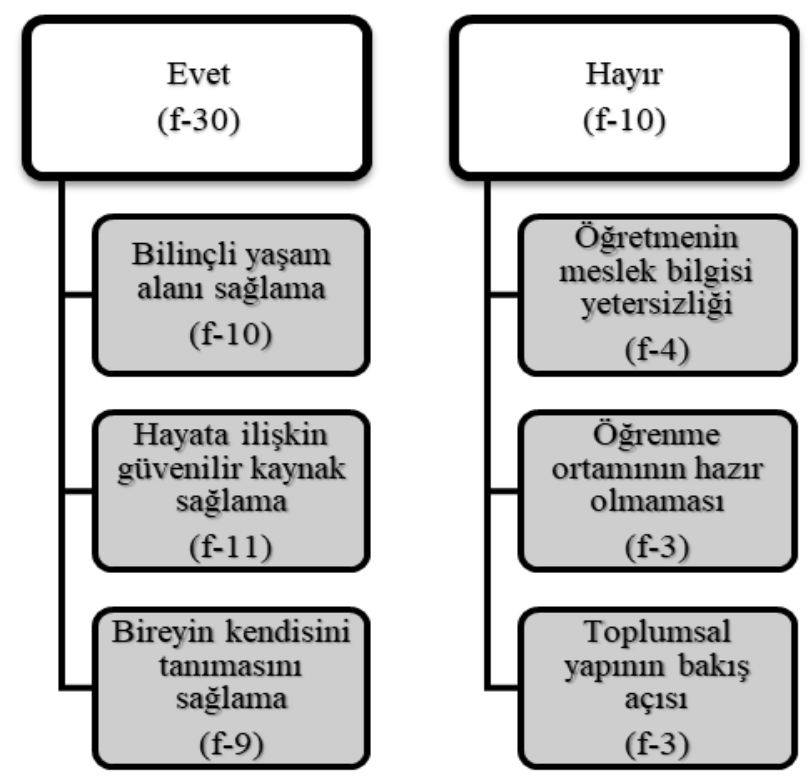

Şekil 2. Çalışma grubu üyelerinin okullarda mahremiyet eğitiminin gerekliliğine ilişkin fikirleri

Şekil 2'ye bakıldığında okul müdürlerinin okullarda mahremiyet gereklilik durumuna yönelik ifade ettikleri gerekçelerin dikkat çekici olduğu söylenebilir. Okul müdürlerinin çoğunun mahremiyet eğitiminin okullarda verilmesi gerektiğini belirtmiş ve çeşitli gerekçeler sunmuştur. Müdürlerin birkaçı ise toplumsal yapının mahremiyet eğitimini verecek hoşgörüye/açık fikirliliğe sahip olmaması, okuldaki öğrenme ortamının bu eğitimin aktarılmasına uygun olmaması ve mahremiyet eğitimine ilişkin öğretmen meslek bilgisi yetersizliklerini gerekçe göstererek bu eğitimin okullarda verilmemesi gerektiğini vurgulamışlardır. $\mathrm{Bu}$ eğitimin okullarda verilmesi gerektiğini ifade eden çalışma grubu üyelerinin örneklendirilmiş görüşleri aşağıda verilmiştir. 
"Okullarda mahremiyet eğitiminin verilmesi önemlidir. Doğru, bilimsel bilgiler sağllklı bir şekilde ancak okullarda verilebilir. Kulaktan dolma, yanlış bilgiler ögrencilere okul dişında verildiğinde daha büyük problemlere neden olmaktadır" (Md38). "Okullarda mahremiyet eğitiminin verilmesini kesinlikle gerekli görüyorum. Çünkü mahremiyet eğitimi bir günde verilemeyecek kadar geniş bir olgudur. Zamana yayılarak anlatılmast şarttır. Akranlarından veya akraba ve ailesinden ögrreneceği bilginin doğruluğu konusunda emin olunamaz ve bir takım yanlışlıklar barındırabilir. Ama profesyonel bir şekilde bu ĕgitimin okullarda verilmesini daha doğru buluyorum” (Md12).

Mahremiyet eğitiminin okullarda verilmesinin uygun olmadığını ve bu nedenle gerekli görmediklerini ifade eden çalışma grubu üyelerinin örneklendirilmiş görüşlerine doğrudan yapılan alıntılar aşağıda verilmiştir.

"5 yıllık bir idareci olarak sorduğunuz soruya cevap verirken, okulumda eğitim hayatına devam eden ögrencilerin yetiştiği aile ve çevre ortamını dikkate alarak cevap vermem gerektiğini düşündüğ̈̈mde, bu eğitimi kesinlikle gerekli görmüyorum. Çünkü, görev yaptığım okulun bulunduğu çevre, bu eğitimin okullar aracılığıyla verilmesi konusunda hoşgörü düzeyi yeterli seviyede olmadığını düşünüyorum” (Md32). “Bu ĕgitim, ayrı bir uzmanlık gerektiren bir yeterlilik istediğinden dolayı, mahremiyet eğitiminin okullarda verilmesinin doğru olmadı̆̆ını düşünüyorum. Çünkü görev yapan ögretmenlerimizin bu konuya ilişkin yeterlilik düzeylerinin uygun olmadığını düşünüyorum” (Md34).

\section{Mahremiyet Eğitimine Yönelik Okulda Yapılan Çalışmalara İlişkin Durum}

Okul müdürlerine yöneltilen "Okulunuzda mahremiyet eğitimine yönelik bir çalışmanız var mı, varsa açıklayınız?" sorusuna verilen yanıtlara yönelik bulgular şekil 3'te verilmiştir. Okul müdürlerinin çoğunluğu mahremiyet eğitimine ilişkin okullarında birçok çalışmaya yer verdiklerini ifade etmiştir. Müdürlerin bir ksımı, mahremiyet eğitimine yönelik okullarında herhangi bir çalışma gerçekleştirmediklerini belirtmiş ve çalışma yapmama durumunu bu konuda sorumluluklarının olmaması ve okul aile birliğinin konuya ilişkin bakış açısıyla gerekçelendirdikleri tespit edilmiştir (şekil 3). Çalışma grubunu oluşturan okul müdürlerinin okullarında yaptıkları çalışmalara bakıldığında, cinsiyet eğitimi ve farkındalık çalışmasının ön plana çıktığı söylenebilir. 


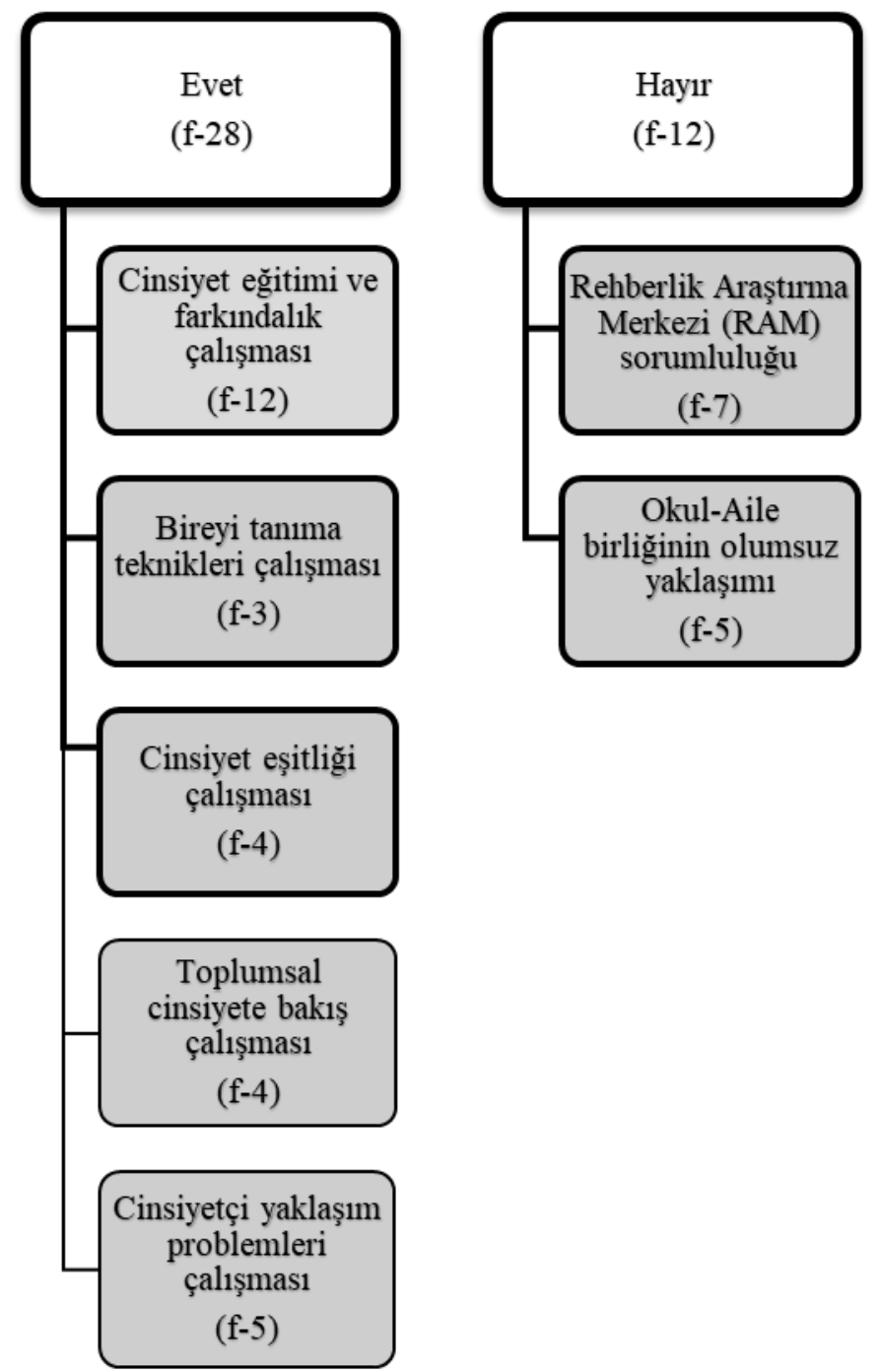

Şekil 3. Çalışma grubu üyelerinin okullarda mahremiyet ĕgitimine yönelik çalışmalara ilişkin fikirleri

Okul müdürlerinin mahremiyet eğitimine ilişkin okullarında yaptığ 1 çalışmalara örnek olarak ifadeleri aşağıda yer almaktadır.

"Bir ilkokul müdürü olarak, mahremiyet (cinsiyet) eğitiminin bireyin gelecek yaşamına ilişkin farkındalık düzeyini arttırmak için çok önemli olduğunu düşünüyorum. Bu nedenle, okulda eğitim hayatına devam eden öğrencilerimizin gelişim özelliklerini de dikkate alarak bireyi tanıma tekniklerine ilişkin rehberlik servisimizde görevli ögretmenlerimizle bir takım çalışmalar gerçekleştiriyoruz" (Md39). 
E.Koçoğlu ve Y.E., Avcı/ Pamukkale Üniversitesi Eğitim Fakültesi Dergisi, 54, 385-409, 2022

"4 ylllık bir okul idarecisi olarak, Türkiye'de eğitim kurumlarında mahremiyet eğitimine ilişkin yeterli düzeyde ĕgitim verilmediğini düşünüyorum. Bu ĕgitim ahlak temelli içeriğinden dolayı sadece aile tarafindan verilir şeklindeki algl, bu durumun temel sebebi olarak ifade edebilirim. Bireysel olarak baktı̆̆ımda, görev yaptı̆̆ım okulda, cinsiyet eşitliğini temele alan bazı çalışmalar, konu uzmanlarını üniversitelerden davet ederek öğrencilerimize vermeye çalışıyoruz” (Md23). "Mahremiyet eğitimine ilişkin çalışmalar evet yapıyoruz. Ortaokul olduğumuz için geçiş sürecinde olan çocukları yaşadıkları veya yaşayacakları değişimleri rehber öğretmen eşliğinde ögrrencilere vermekteyiz. Rehber ögrretmenimiz erkek olduğu için erkeklere kendisi semine vermekte ve kız öğrencilere să̆lık ocă̆ından bir hemşire eşliğinde seminerler verilmektedir" (Md12).

Mahremiyet eğitimine ilişkin görev yaptıkları herhangi bir çalışma yapmadıklarını ifade eden bir müdürün ifadesi aşağıda verilmiştir.

"Mahremiyet ĕgitimine yönelik herhangi bir çalışma, bugüne kadar görev yaptı̆̆ım okullarda vermediğimizden dolayı şuanda da görev yaptı̆̆ım okulda herhangi bir çalışma yapmadık. Ben bir okul müdürü olarak, bu eğitime ilişkin çalışmaların okullardan ziyade Rehberlik Araştırma Merkezlerinin sorumluluğunda olduğunu düşünüyorum ve bir çalışma yapılacaksa onların yapması gerektiğini düşünüyorum" (Md2).

\section{Mahremiyet Eğitiminin İçeriğine İlişkin Durum}

Okul müdürleri “Sizce mahremiyet eğitiminin içeriğinde neler olmalıdır?” sorusuna dikkat çekici yanıtlar vermiştir. Çalışma grubunu oluşturan okul müdürlerinin, mahremiyet eğitimi içeriğinde daha çok cinsiyet eğitimi ve süreçlerine yönelik konulara değinmişlerdir. $\mathrm{Bu}$ durum, çalışma grubu üyelerinin, cinsiyet eğitimine ilişkin farkındalık düzeylerinin yüksek olmasından kaynaklanabilir. Bu farkındalığın mahremiyet eğitimi kapsamında cinsiyet eğitimine ilişkin bir takım çalışmaların okullarda yapılmasına katkı sağladığı söylenebilir. 


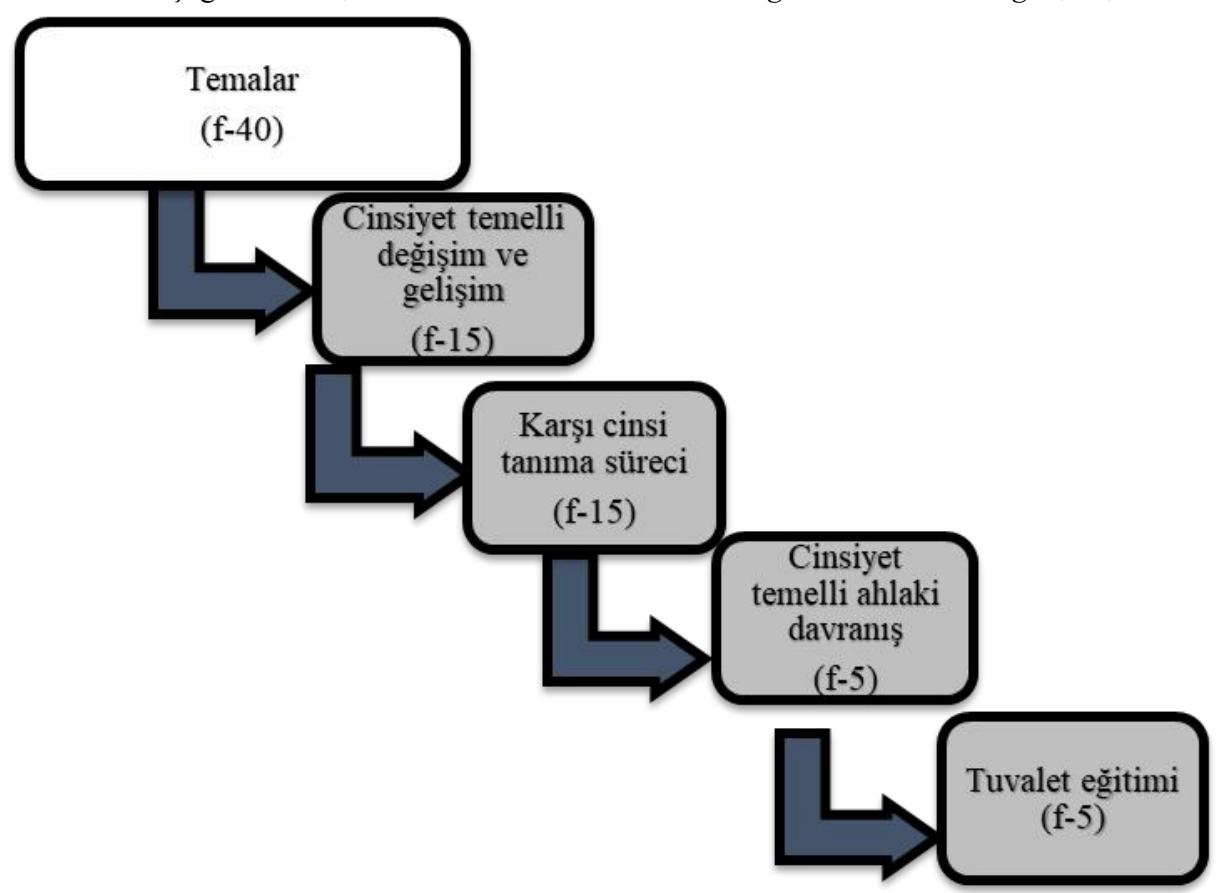

Şekil 4. Çalışma grubu üyelerinin mahremiyet eğitiminin içeriğine ilişkin fikirleri

Okul müdürlerinin örneklendirilmiş cümleleri aşağıda verilmiştir.

"Mahremiyet ĕgitimi denilince bende çă̆rışım yapan kavramların çoğu cinsiyet eğitimiyle benzerlik göstermektedir. Daha doğrusu, bireyin ait olduğu cinsiyete ait davranışları, vatandaşı olduğu ülkenin hukuk kuralları ve yaşadiğı çevrenin ahlak kurallarıyla çatışmadan sergilemesidir. Bu nedenle ben sorunuza cevap olarak mahremiyet eğitiminin içeriğini, cinsiyet temelli sergilenen davranışların ahlak sınırını aşmadan değerlendirme süreci olarak tanımlamak istiyorum” (Md1). “Genel olarak, mahremiyet ĕgitimi denildiğinde içerik olarak, cinsel bilgiler ve cinselliğe bă̆lı bedensel özellikler verilmeli. Örneğin ergenlik dönemi özellikleri, karşı cins bilgileri, döneme bağlı bedensel bilgiler ve bedenin özellikleri verilebilir” (Md10).

“Mahremiyet ĕgitimi kapsamında tuvalet ĕgitimi, kişisel temizlik ve bakım, kendi bedenini tanıma, vücudunu koruma, yakınlı mesafesi ve kişisel alanın belirlenmesi gibi konulara değinilmesi gerektiğini düşünüyorum” (Md13).

\section{Mahremiyet Eğitiminin Aktaranına İlişkin Durum}

Araştırmada mahremiyet eğitiminin kimler tarafından verilmesi gerektiğiyle ilgili olarak, çalışma grubunu oluşturan okul müdürlerine "Mahremiyet eğitimi okullarda kim ya da kimler tarafından verilmeli, niçin?” sorusu yöneltilmiştir. Alınan cevaplar analiz edildikten sonra ulaşılan bulgular temalar şeklinde şekil 5'te gösterilmiştir. 


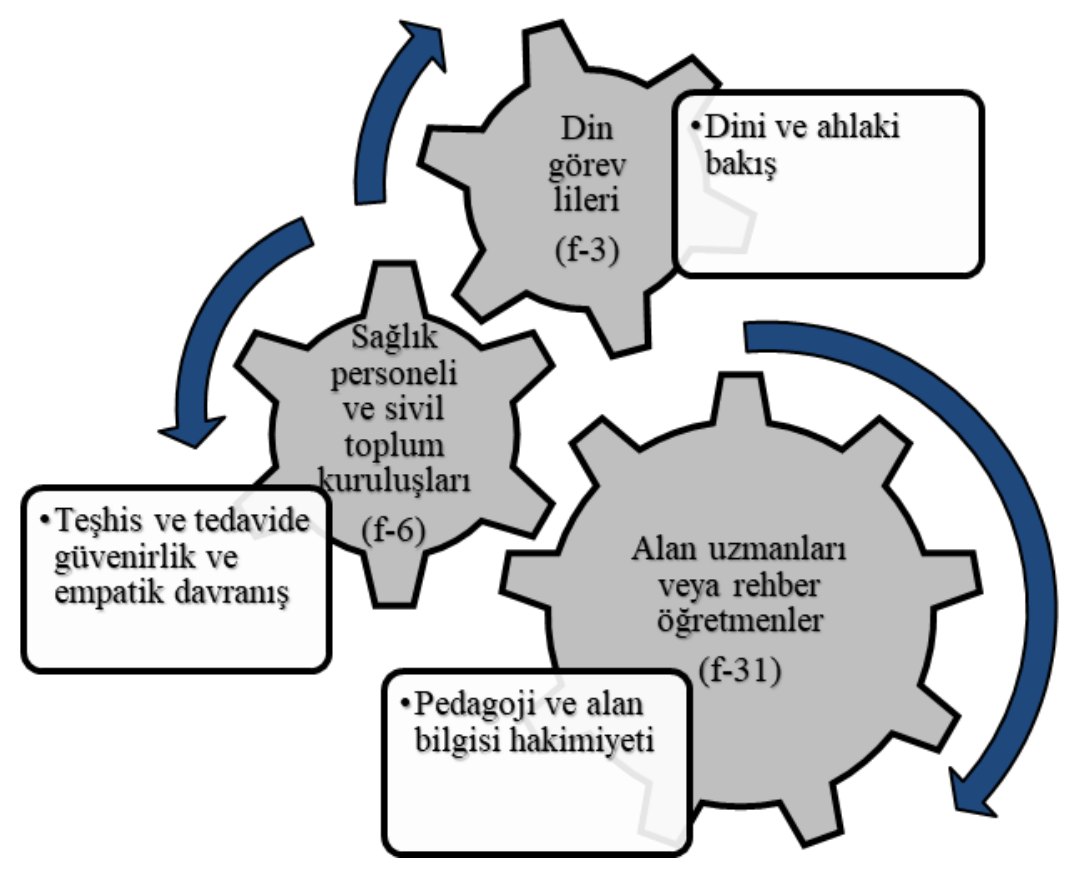

Şekil 5. Çalışma grubu üyelerinin mahremiyet ĕgitiminin kim tarafindan verilmesi gerektiğine ilişkin fikirleri

Mahremiyet eğitiminin kim tarafından verilmesi gerektiği konusunda, çalışma grubu üyelerinin üç gruba ayrıştığı tespit edilmiştir (şekil 5). Ancak her üç grupta yer alan meslek elemanlarının nitelikli ve profesyonel olması koşulu vurgulanmıştır. Okul müdürlerinin örnek ifadeleri aşağıda yer almaktadır.

"Bence, mahremiyet ĕgitimi, profesyonellerin vermesi gereken bir eğitim olduğundan dolayl, bu alanda yetişmiş ve yeterlilik düzeyi olduğuna dair belgesi olan, alan uzmanları ya da rehber ögretmenler tarafindan verilmelidir. Çünkü bireyin gelişim sürecinde sergileyeceği davranışları gelişim dönemleri içerisinde en iyi tanımlayabilen meslek elemanlarının bunlar olduğunu düşünüyorum” (Md44). "Mahremiyet ĕgitimi, toplum ve aile temelli bakıldı̆̆ında güven indeksi oldukça yüksek olması gereken meslek elemanlar tarafindan verilmesi gerektiğini düşünüyorum. Bunlarda bana göre belge ve kanıtla konuşan ve açıklayan să̆lıkçılardır. Bu nedenle mahremiyet ĕ̆itimi, bu konuda uzman kendini yetiştirmiş sağlıkçılar tarafindan verilmelidir" (Md7). "Rehber öğretmenler, sağlıkçılar ve müftülük çalışanları vasıtasıyla verilebilir. Bu alanın pedagojik uzmanları rehber ögretmenler sağlık ve fiziksel durum hakkında uzman sağlıkçılar ve mahremiyetin etik yönünü bilenler de müftülük personelidir. Tüm bu profesyonel ekip tarafindan ortak bir platformda eğitim verilmelidir (Md3). 


\section{Mahremiyet Eğitimi ve Medya Arasındaki İlişki Durumu}

Çalışma grubu üyelerine yöneltilen "Size göre günümüzde medya araçlarının mahremiyet eğitimi üzerinde olumsuz bir etkisi var mıdır, neden?” şeklindeki soruya dikkat çekici yanıtların verildiği şekil 6'da yer alan bulgulardan hareketle söylenebilir. Çalışma grubu üyelerinin mahremiyet eğitimi ve medya arasındaki etkileşimi değerlendirmelerinde; müdürlerin tamamına yakını (f-35) mahremiyet eğitiminin medyadan olumsuz etkilendiğini ifade ederken bu durumu farklı temalarda gerekçelendirmişlerdir (şekil 6). Müdürlerden bir kısmının, medyanın mahremiyet eğitimi üzerinde, medyanın aile denetimi doğrultusunda kullanımı ve medyanın şifreleme siteminin var olmasından dolayı herhangi bir olumsuz etkisinin olmadığını ifade ettikleri tespit edilmiştir (Şekil 6).
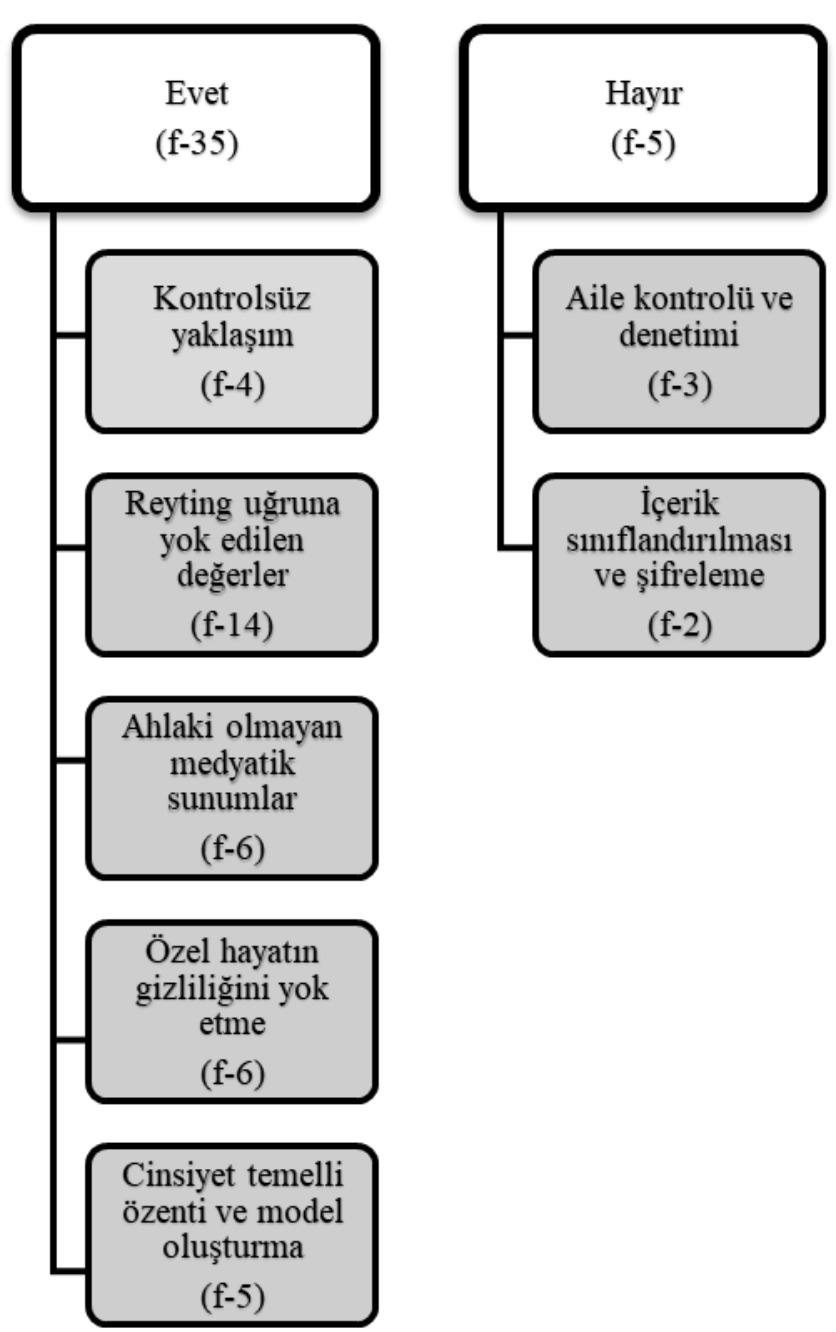

Şekil 6. Çalışma grubu üyelerinin mahremiyet eğitimi medya etkileşimine ilişsin görüşleri

Okul müdürlerinin örnek görüşleri aşağıda verilmiştir. 
"Bir okul müdürü ve baba olarak çok önemli bir soru sorduğunuzu düşünüyorum. Mahremiyet ĕgitiminden önce mahrem (sakl, gizli, günah, haram) kelimesini yok eden birçok programın medyada yer aldığını görüyoruz. Bu durum, çocuklarımızın ve gençlerimizin mahremiyet algısını ne yazık ki ortadan kaldırmaktadır. 1980'li yıllarda mahremiyet eğitimine ilişkin 20 yaşındaki bir gencin utanarak sorup öğrendiği bir problemi günümüzde bir çocuk 7-8 yaşlarında medya aracılı̆̆ıyla çok rahat ögrenebiliyor. Bu durum, mahremiyet eğitiminin çocuklarımızın ve gençlerimizin gözünde değersizleşmesine sebep olduğunu söyleyebilirim. Peki, ne yapmallyız derseniz medyayı belli bir yaş düzeyine kadar çocuklarımıza kontrollü kullandırtmalıyız derim” (Md21). "Unutulmamalıdır ki, hiçbir ekonomik kazanç çocuklarımızdan gençlerimizden daha önemli değildir. Çünkü bunlar, yarınlarımızı inşa eden birer öğretmen, doktor, mimar, mühendis vb. adaylardır. Geleceğimizi yok etmek istemiyorsak, sağlam mahremiyet algısına sahip bir nesil yetiştirmeliyiz. Bu nedenle ekonomik kazanç uğruna reyting temelli mahrem olmayan medya programlarına kesinlikle izin verilmemelidir” (Md11). Olduğunu düşünüyorum. Çünkü reklam amaçlı dahi olsa cinsel içerikli öğeler telefon, tablet ve bilgisayarda karşısına çıkmakta ve ister istemez ergenliğe yeni giren öğrencileri kendine çekmektedir. Mahremiyette sınır tanımayan ve cinsel olarak etkileyici olan bu tür içerikler vasıtasıyla mahremiyet ortadan kaldırılmaktadır (Md12).

\section{Tartışma ve Sonuç}

$\mathrm{Bu}$ araştırmanın amacı, okul müdürlerinin bakış açılarından mahremiyet eğitimini değerlendirmektir. Fenomenolojik yaklaşımla tasarlanan nitel araştırmada kamu okullarında görev yapan 40 okul müdürü ile çevrimiçi görüşmeler yapılarak veriler alınmış ve veriler içerik analizi tekniğiyle analiz edilerek sunulmuştur. Araştırma sonuçları sırayla verilmiştir.

Okul müdürlerinin mahremiyet tanımlarında ön plana çıkan kısım kişiye özel olan; bilgi, alan, özellikler ve cinsel bilgilerdir. Mahremiyet tanımlamalarında gizlilik, adap ve sınır kavramlarıyla açıklanabilen farklı örneklere de değinilmiştir. Mahremiyet insanlık tarihi kadar eskilere dayanır, ancak dönemsel ve toplumsal tanımlamalarda farklılıklar olduğu gibi neyin özel olduğu ve korunması gerektiği de farklılık gösterebilir (Lukács, 2016). Nitekim günümüzde bedensel mahremiyet hukuk ve ortak ahlak düzenlemelerimizde yer alan en değerli haklarımızdan biri olmasına rağmen mahremiyet eğitiminin yeterliliklerine sahip olma düzeyi, daha yüksek statüye ulaşabilmiş değildir (More, 2003). Çalışmada ön plana çıkan genel sonuç, mahremiyet kavramının cinsellik kavramıyla ifade 
edilmesidir. $\mathrm{Bu}$ sonuç doğrultusunda yapılan çalışmalara bakıldığında, Çalışkan (2019), araştırmasında okul öncesi öğretmenleri örnekleminde, öğretmen ifadelerine göre mahremiyeti daha çok cinsellik ve bedensel özelliklerle ilişkilendirmiştir. Çakır (2015) araştırmasında, velilerin mahremiyet tanımlarında yoğun olarak araştırmamıza benzer şekilde "gizlilik, dokunulmazlık, kişinin özel alanı" kavram ve olguları doğrultusunda mahremiyet tanımlamalarına ulaşmıştır. Yine Duran (2018), kuramsal çalışmasında mahremiyet eğitimin ilkeleri kapsamında çocuklara özel bir alan oluşturma, sınır koyma ve cinsel konulara temas etmiştir. Hekimoğlu (2019), mahremiyeti "kişisel mahremiyet, mekânsal mahremiyet ve enformasyon mahremiyeti” boyutları altında incelemiştir.

Mahremiyet eğitiminin gerekliliği ve sebebi konusunda okul müdürlerin büyük çoğunluğu okullarda mahremiyet eğitimi verilmesinin lüzumunu çeşitli gerekçeler belirterek ifade etmiştir. Mahremiyet eğitiminin verilmesini gerekli görmeyen müdürler ise gerekçe olarak öğretmenden, okuldan veya toplumdan kaynaklanan bir takım eksikleri/aksaklıkları sunmuşlardır. Dolayısıyla müdürlerin tamamının okullarda mahremiyet eğitimini gerekli gördükleri, fakat uygun koşulların sağlanmasının gerekçe olarak ileri sürmüşlerdir. Okul müdürlerinin mahremiyet eğitiminin gerekliliği konusunda belirttiği iki temel gerekçe öğrencilerin hayat ilişkin konularda güvenilir kaynaklardan beslenmesini sağlamak ve bu eğitim vasıtasıyla öğrencileri bilinçlendirerek olumsuzluklardan korumaktır. Benzer şekilde Çakır (2015) ve Türkyılmaz’ın (2019) veliler üzerinde yaptı̆̆ı araştırmalarda velilerin tamamı mahremiyet eğitimini gerekli görmüştür. Özellikle etkin bir şekilde okul öncesi dönemde kazandırılması gereken mahremiyet eğitimi okul öncesi öğretmenlerince de farklı gerekçelerle önemli görülmektedir (Çalışkan, 2019). Nitekim Duran (2018), araştırmasının sonuçlarına dayalı olarak sağlıklı bir toplum oluşturmak için mahremiyet eğitiminin özellikle öğrenciler başta olmak üzere toplumun her kesimine verilmesi gerektiğini ifade etmektedir.

Okullarda mahremiyet eğitimine yönelik herhangi bir çalışma yapılıp yapılmadığ konusunda müdürlerin çoğunluğu özellikle rehberlik servisi faaliyetleri kapsamında cinsiyet ve cinselliğe yönelik bazı çalışmaların yapıldığını ifade etmiştir. Müdürlerin birkaçı okullarında herhangi bir çalışma olmadığını belirtmiştir. Müdürlerin tamamı uygun koşulların oluşması halinde mahremiyet eğitimini gerekli bulurken birkaç müdürün okullarında herhangi bir faaliyet yapmaması kendi fikirleriyle tezat oluşturmaktadır. $\mathrm{Bu}$ müdürlerin mahremiyet eğitimine yönelik faaliyetleri gerekli görmesine rağmen herhangi bir çalışma yapmıyor olması farklı gerekçelerle kayıtsız kaldığı anlamına gelebilir. Okul 
müdürlerinin önemli bir işlevi olan eğitim öğretim alanında faaliyetlerin yürütülmesi kapsamında gerekli gördügü bir alanda pasif kalması uygulamada bazı aksaklıkların olduğunu gösterebilir.

Mahremiyet eğitiminin içeriğine yönelik olarak okul müdürleri daha çok cinsiyet eğitimi ve süreçlerine yönelik konulara değinmişlerdir. Bu durum, çalışma grubu üyelerinin, cinsiyet eğitimine ilişkin farkındalık düzeylerinin yüksek olmasından kaynaklanabilir. Çalışkan (2019) da araştırmasında mahremiyet eğitiminin amaçlarıyla ilgili olarak; çocuğun kendini korumasını sağlamak ve özel bölgeleri öğretmek konusuna değinmiş ve mahremiyet eğitiminde mahremiyet ve cinselliğe vurguda bulunmuştur. Sadece birkaç müdür tarafından ifade edilen tuvalet eğitimi okulöncesi dönemde kazandırılması gereken birçok beceriyi içeren önemli süreçlerden birisidir. Mahremiyet eğitimi cinsel bilgileri de içine alan fakat cinsel gelişimin yoğun olduğu ergenlik döneminden çok önce başlayan, temelleri kişilik gelişiminin büyük bir kısmının oluştuğu 0-6 yaş gurubunda verilmesi gereken önemli bir eğitimdir (Duran, 2018). Tuvalet eğitimi de mahremiyet unsurlarını barındırmakla beraber bu döneme geçilmeden önce bebeğin altını başkalarının yanında değiştirmemek de mahremiyeti hissettirmek ve kavratmak adına yapılması gereken davranışlardandır. $\mathrm{Bu}$ açıdan bakıldığında mahremiyet eğitimi daha kapsamlı boyutlarda ele alınmalıdır. Nitekim Çelikoğlu (2007), üniversite öğrencileri örnekleminde yaptığı araştırmasında mahremiyeti katılımcı ifadelerine göre 8 boyutta ele almış ve "bedenin mahremiyeti, evin mahremiyeti, aile mahremiyeti, kişiler arası ilişkilerde mahremiyet, cinsellik ve sözün mahremiyeti gibi farklı şekillerde daha kapsamlı olarak ele almıştır. Baysal Berkup (2015), mahremiyeti; beden mahremiyeti, ev mahremiyeti, kadın erkek ilişkileri mahremiyeti ve dini, siyasi görüş mahremiyeti olarak 4 alt boyutta ele almıştır. Çakır (2015), çocuklarda mahremiyet eğitimi üzerinde din eğitiminin rolünü araştırdığı çalışmasında veliler mahremiyet eğitimiyle ilgili konularda araştırmamızdan farklı olarak "yatak odalarına izinsiz girmeme" "kılık, kıyafet, tesettür" "karı-koca ilişkileri” “internet ve TV'nin bilinçli kullanımı” gibi farklı konulara da değinmişlerdir. $\mathrm{Bu}$ farklılık okullardaki mahremiyet eğitiminden farklı olarak aile hayatından başlayarak ebeveyn örnekleminde araştırma yapılmasından kaynaklanabilir. Velilerin çoğunluğu tarafından mahremiyet eğitiminin 4 yaş ve öncesinde başlaması gerektiğinin kabul edilmesinden dolayı cinselliğin daha kavranmadığı dönemlerde de mahremiyet eğitiminin verilmesi gerektiğinin altını çizmektedir.

Mahremiyet eğitiminin okullarda kimler tarafından verilmesi gerektiğiyle ilgili olarak okul müdürlerinin tamamı mahremiyet eğitiminin uzman ve bu konuda deneyim 
sahibi kişilerce verilmesi gerektiğini belirtmişlerdir. Farklı kişi ve kurumlardan bu eğitimi verebilecek kimselere değinen müdürlerin temel talepleri bu konuda uzmanlık yeterliğine sahip kimseler olmasıdır. Benzer şekilde Çalışkan (2019) araştırmasında okul öncesi öğretmenlerin tamamına göre mahremiyet eğitiminin aile, öğretmen ve uzmanlar tarafından verilmesi gerektiğini tespit etmiştir. Okul tarafından verilen cihazlar ve öğrenci mahremiyeti konusunda öğretmenlerin bir uzman olarak casusluğu engellemek adına uyguladıkları programda dijital okuryazarlık ve mahremiyet eğitimini mevcut müfredatlarına entegre ederek vermesi gerektiği tavsiye edilmektedir (Electronic Frontier Foundation, 2017). Teknoloji araçlarının mahremiyet eğitimine etkisine yönelik olarak müdürlerin tamamına yakını günümüz teknoloji araçlarının mahremiyet eğitimini olumsuz etkilediğini ifade etmiştir. Müdür ifadelerine bakıldığında genel olarak teknoloji araçlarının mahremiyet üzerinde sunduğu içerik bakımından bir takım olumsuz etkilerinin olduğu tespit edilmiştir. Aile denetimi bu etkiyi pozitif yöne çevirmek adına gerekli görülmüş ve özellikle sosyal medya ve dijital teknoloji araçları vasıtasıyla iletilen birçok içeriğin mahremiyeti yıpratıcı özellikte olduğu vurgulanmıştır. Özellikle gençler için bu durum, endişe verici sonuçlar ortaya çıkarabilmektedir. Sanal platformlarda her tür bilgi kontrolsüz bir şekilde dolaştı̆̆ için mahremiyet ihlallerine ve bireylerin mahremiyet algılarında dönüşümlere yol açabilmektedir (Korkmaz, 2012; Karagülle, 2015; Hacıbekiroğlu, 2019). Sengupta ve Chaudhuri (2011), 12-17 yaş aralığındaki gençlere yönelik yaptıkları çalışma ile bilgisayarlarını ebeveynlerinden gizli kullanan gençlerin sanal ortamlarda zorbalığa daha fazla maruz kaldıklarını ortaya koyarak ebeveynlerin çocuklarıyla etkileşiminin önemini vurgulamaktadır. Sosyal medyada mahremiyet, kişisel verileri ifşa edebilme hakkı olarak ifade edilebilirken gençlerde kendileri veya başkaları tarafından mahremiyet sınırlarını aşacak paylaşımların ortaya çıkması karşılaşılan gelen bir durum olmuştur. Özellikle 15-30 yaş arası gençlerin yoğun bir şekilde sosyal ağ kullanımı ve günlük hayatlarını İnstagram gibi sosyal paylaşım sitelerinde sergilemesi söz konusudur (Sığın, 2019). Çünkü internet kullanımı çağında, yalnızca geleneksel iletişim biçimi tamamen dönüştürülmekle kalmamış insanlar, neredeyse hiçbir sınır olmaksızın hayatlarının (veya başkalarının) en samimi anlarını paylaşabilecek (sosyal medyanın aşırı popülerliğini düşünmek yeterlidir) duruma gelmişlerdir (Lukács, 2016). Dijitalleşme sürecinin hızlanması ve yeni teknolojilerin gelişmesiyle yaygınlaşan sosyal ağlar, mahremiyet algısının dönüşmesine ve ihlalinin artmasına sebep olmuştur (Hekimoğlu, 2019). İletişim amacıyla kullanılan araç ve gereçler, tüm sınırları, duvarları kaldırmış ve her bir olguyu görünür ve gösterilebilir kılmıştır. Bu vesileyle başlangıçta bir yeni buluş, keyifli bir araç olarak karşılanan teknolojik gelişmeler, 
zamanla toplum için tehditler oluşturan mekanizmalara dönmüştür (Lemke, 2014). Nitekim Digital in 2020 Global Overview raporuna göre 2020 yılında dünya nüfusunun \%59’u (4.54 milyar) küresel internet kullanıcısıdır ve \%45'i sosyal medya kullanmakta olduğunu bildirmiştir. Raporda, dünya nüfusunun \%49'unun aktif sosyal medya kullanıcısı olduğu belirtilmiştir (wearesocial.com). Araştırmalar, gençlerin sosyal medyada çok aktif olduklarını, büyük miktarda kişisel bilgileri çevrimiçi olarak paylaştıklarını ortaya koymaktadır (Culver ve Grizzle, 2017). Sosyal medya bağımlılığının da gençleşmeyle doğru orantılı olarak arttı̆̆ ortaya çıkmıştır (Kaya, 2019). Sengupta ve Chaudhuri (2011), 12-17 yaş aralığındaki gençlere yönelik yaptıkları araştırmaya göre katılımcılar, sosyal ağlarda, tüm kullanıcıların erişebileceği fotoğrafları yüklemenin, kişisel bilgileri ifşa etmenin, çevrimiçi sohbet odalarını ziyaret etmenin; istenmeyen yabancı temasların veya çevrimiçi zorbalığın anahtarı olduğunu ifade etmişler ve özellikle kızların, çevrimiçi tacize daha fazla savunmasız olduğunu ortaya koymuşlardır. Ortaokul öğrencilerine yönelik yapılan araştırmada öğrencilerin \% 24'ünün sosyal ağlarda siber zorbalığa karıştığı, erkeklerin kızlara göre bu ortamlarda daha fazla suç içeren davranışlarda bulunduğu ve zararlı gruplara daha fazla katıldıkları ortaya çıkmıştır (Baştürk-Akca, Sayımer ve Ergül, 2015). Elem Yıldırım (2017), araştırmasında çocukların internetteki mahremiyet ihlalleri konusunda önemli bir risk gurubu olduğunu ortaya koymuştur. Kitle iletişim araçları kullanımının verebileceği zararları ortadan kaldırmanın yolu mahremiyetten bilincinden geçer. Bu konuda hassasiyet göstermesi gerekenler öncelikle kişinin kendisi ve ailesidir (Duran, 2018). Her an doğrudan bir denetimin sağlanmasının çok güç olduğu bu mecrada en önemli tedbir, kişinin kendi mahremiyet alanını bizzat kendisinin oluşturması ve korumasıdır (Çekiç, 2019). Fakat erken yaşta çocukların öz denetimi güç olduğundan dolayı ailelere büyük sorumluluklar düşmektedir. $\mathrm{Bu}$ durum çocukların dijital platformlardan yararlanma ve onları kullanımı konusunda, ebeveynlerin planlı etkinlikler gerçekleştirmesini beraberinde getirdiği söylenebilir (Majedi, Ghazinour, Chinaei and Barker, 2009; Saeri, Ogilvie, La Macchia, Smith and Louis, 2014). Yapılan bu araştırmada elde edilen sonuçlardan hareketle;

$\checkmark$ Mahremiyet eğitiminin içeriğine ilişkin yetkili kurumlar tarafından görsel içerikler oluşturulmalı ve bunlar okullarda dikkat çekici şekilde sergilenmelidir,

$\checkmark$ Mahremiyet eğitiminin önemine ilişkin, bireyin gelişimi üzerinde etkili olan herkese (Ebeveyn, okul müdürü, öğretmen vb.) gerekli eğitimler verilmelidir,

$\checkmark$ Mahremiyet eğitimi kapsamında bireyin medya araçlarını kullanma amacı ve şekli ebeveynler tarafindan kontrol edilmelidir, 
$\checkmark$ Mahremiyet eğitimine ilişkin yeterliliklere sahip uzman öğretmen sayısını arttırmak amacıyla, öğretmenlik meslek bilgisi dersleri kapsamında bu eğitim, lisans düzeyinde öğretmen adaylarına kazandırılmalıdır şeklinde öneriler sunulabilir.

Etik Kurul İzin Bilgisi: Bu araştırma, İnönü Üniversitesi Sosyal ve Beşerî Bilimler Bilimsel Araştırma Etik kurulunun 30/06/2021 tarihli 2021/13-20 sayll kararı ile alınan izinle yürütülmüştür.

Yazar Çıkar Çatışması Bilgisi: Yazarların beyan edeceği bir çıkar çatışması yoktur.

Yazar Katkısı: Birinci yazar, teorik çerçevenin oluşturulması, veri analizi, bulgular, sonuç ve tartışma kısmında katkı sağlamıştır. İkinci yazar, teorik çerçevenin oluşturulması, bulgular, sonuç ve tartışma, öneriler kısmında katkı sağlamıştır.

\section{Kaynakça}

Altunışık, R., Coşkun, R., Yıldırım, E., \& Bayraktaroğlu, S. (2001). Sosyal Bilimlerde Araştırma Yöntemleri. Sakarya: Sakarya Kitabevi.

Aydın Avşar, S.(2018). Anne-baba ve ergen çocukların mahremiyet algısındaki farklılıkların sosyal medya üzerinden okunması. İstanbul Sabahattin Zaim Üniversitesi Sosyal Bilimler Enstitüsü, Yayımlanmamış Yüksek Lisans Tezi.

Baştürk-Akca, E., Sayımer, İ., \& Ergül, S. (2015). Ortaokul öğrencilerinin sosyal medya kullanımları ve siber zorbalık deneyimleri: Ankara örneği. Global Media Journal: Turkish Edition. 5(10), 71-86.

Baysal Berkup, S. (2015). Sosyal ağlarda bireysel mahremiyet paylaşımı: x ve y kuşakları arasında karşılaştırmalı bir analiz. Yayımlanmamış doktora tezi. Ege Üniversitesi Sosyal Bilimler Enstitüsü. İzmir.

Culver, S. H., \& Grizzle, A. (2017). Survey on privacy in media and information literacy with youth perspectives. Paris: UNESCO Publishing.

Çakır, S. (2015). 4-6 yaş aralı̆̆ındaki çocuklara mahremiyet ĕgitimi verilmesinde din eğitiminin rolü (Sivas Örneği). Yayımlanmamış yüksek lisans tezi. Cumhuriyet Üniversitesi Sosyal Bilimler Enstitüsü. Sivas. 
Çalışkan, H. (2019). Okul öncesi dönemde çalışan öğretmenlerin mahremiyet eğitimi konusunda bilgi düzeylerinin belirlenmesi. Yayımlanmamış yüksek lisans tezi. Necmettin Erbakan Üniversitesi Eğitim Bilimleri Enstitüsü. Konya.

Çekiç, S. (2019). İslam hukukunda mahremiyet ve sosyal medya. Yayımlanmamış yüksek lisans tezi. Çanakkale Onsekiz Mart Üniversitesi Sosyal Bilimler Enstitüsü. Çanakkale.

Çelikoğlu, N. (2007). Türkiye’de üniversite gençliğinde mahremiyetin dönüşümü. Yayımlanmamış yüksek lisans tezi. Marmara Üniversitesi Sosyal Bilimler Enstitüsü.

Diler, R. (2015). “Mahremiyet Eğitimi ve Önemi”, Erişim: 01.04.2020, http://earsiv.gop.edu.tr/xmlui/bitstream/handle/123456789/776/ramazan_diler.pdf?se quence $=1$ İstanbul.

Duran, H. E. (2018). Dĕgerler Ĕgitimi Bağlamında Mahremiyet Ĕ̆itimi. Yayımlanmamış Yüksek Lisans Tezi. Ondokuz Mayıs Üniversitesi. Sosyal Bilimler Enstitüsü. Samsun.

Elektronic Frontier Foundation, (2017). Öğrenci casusluğu, okul tarafindan verilen cihazlar ve öğrenci gizliliği. https://www.eff.org/tr/node/95598 Erişim tarihi: 28.11.2020.

Elem Yıldırım, F. (2017). Medya psikolojisi bağlamında internet kullanıcılı̆̆ı ile oluşan endişeler: mahremiyet endişesi. Yayımlanmamış Doktora Tezi. Marmara Üniversitesi Sosyal Bilimler Enstitüsü. İstanbul.

Eraslan, E., Ergüt İ.K., Uysal, T., \& Bulut, G. (2017). Mahremiyet eğitimi çalıştayı sonuç raporu. Ercüment Erbay (Ed.) Yayın No: 06 Ankara: Aile ve Sosyal Politikalar Bakanlığı. https://cocukhizmetleri.aile.gov.tr Erişim tarihi: 20.12.2020.

Giddens, A. (2014). Modernite ve bireysel kimlik-geç modern çă̆da benlik ve toplum. İstanbul: Say.

Güneş, A. (2015). Nezaket ve zerafet için mahremiyet eğitimi. İstanbul: Timaş yayınları.

Hacıbekiroğlu, M. (2019). Sosyal Medya Kullanımına Bağlı Değişen Mahremiyet Algısı ve Dindarlık İlişkisi. Yayımlanmamış yüksek lisan tezi. Necmettin Erbakan Üniversitesi Sosyal Bilimler Enstitüsü. Konya.

Hekimoğlu, H. (2019). Sosyal ağlarda mahremiyetin dönüşümü: instagram örneği. Yayımlanmamış yüksek lisans tezi. Erciyes Üniversitesi Sosyal Bilimler Enstitüsü. Kayseri. 
Jago, R., Davison, K. K., Brockman, R., Page, S. A., Thompson, L. J., \& Fox, R. K. (2011). Parenting styles, parenting practices, and physical activity in 10-to 11- Year Olds. Preventive Medicine, (52), 44-47.

Karagülle, A. E. (2015). Günümüzde değişen mahremiyet algısının sosyal ă̆lar bağlamında incelenmesi. Yayınlanmamış yüksek lisans tezi. İstanbul Ticaret Üniversitesi Sosyal Bilimler Enstitüsü. İstanbul.

Kaya, A. (2019). Üniversite Öğrencilerinde Sosyal Medya Kullanımı İle Mahremiyet Algısı Arasındaki İlişkinin İncelenmesi. Yayımlanmamış yüksek lisans tezi. Üsküdar Üniversitesi Sosyal Bilimler Enstitüsü. İstanbul.

Korkmaz, İ. (2012). Facebook ve mahremiyet: görmek ve gözetle(n)mek. "facebook and privacy: see and watch/being watched". Yalova Sosyal Bilimler Dergisi.

Köksal Akyol, A. (2015). Okul öncesi eğitimin amaçları ve ilkeleri. Aysel Köksal Akyol (Ed.). Okul Öncesi Eğitim Programları. Her Yönüyle Okul Öncesi Ĕ̆itim-7 içinde. (s.169-176). Ankara: Hedef yayınları.

Lemke, T. (2014). Biyopolitika. (Çev.) U. Özmakas, İstanbul: İletişim Yayınları.

Litt, E. (2013). Understanding social network site users' privacy tool use. Computers in Human Behavior, 29, 1649-1656.

Livberber Göçmen, T.(2018). Toplumsal yaşamda bireylerin mahremiyet yönelimleri: Sosyal ă̆ kullanıcıları üzerine bir saha araştırması. Konya Selçuk Üniversitesi Sosyal Bilimler Enstitüsü Yayımlanmamış Doktora Tezi.

Lukács, A. (2016). What is Privacy? The History and Definition of Privacy. In: Keresztes, Gábor (ed.):Tavaszi Szél 2016 Tanulmánykötet I, Budapest, 15- April. Budapest: Doktoranduszok Országos Szövetsége, pp. 256-265. Available from: https://www.semanticscholar.org/paper/What-is-Privacy-The-History-andDefinition-of-Adrienn/430bfacbabb89c0033b6dcceddc18ba9bbc02c5f [Accessed 30 December 2020].

Majedi, M., Ghazinour, K., Chinaei, A., \& Barker, K. (2009) SQL privacy model for social networks. In the Proceedings of the IEEE International Conference on Advances in Social Network Analysis and Mining (ASONAM). Greece. 2 pages.

Mills, C. W. (2001). “Sosyolojik imgelem”. (Ed. Uğur Dolgun). Sosyo-ekonomik perspektif (s. 79-107). Bursa: Asa.

More, A. D. (2003). Prıvacy: 1ts meanıng and value. American Philosophical Quarterly. 40 (3), 124-168. 
Özaslan, H., \& Gültekin Akduman, G.(2020). Ailelerin mahremiyet eğitimine ilişkin görüşlerinin incelenmesi. SETSCI Conference Indexing System, 3 (2018), 1363-1 369.

Özen, Y. \& Gül, A. (2007). Sosyal ve eğitim bilimleri araştırmalarında evren-örneklem sorunu. Kazım Karabekir ĕgitim Fakültesi Dergisi, 15, 394-422.

Saeri, A. K., Ogilvie, C., La Macchia, S.T., Smith, J. R., \& Louis, W. R. (2014). Predicting Facebook users' online privacy protection: Risk, trust, norm focus theory, and the theory of planned behavior. The Journal of Social Psychology, 154(4), 352-369.

Sengupta, A., \& Chaudhuri, A. (2011). Are social networking sites a source of online harassment for teens? evidence from survey data. Children and Youth Services Review. 33(2), 284-290.

Sepetci, T. (2017). Dijital Oyunlar, Dijital Oyuncular: Karşı Hegemonya Pratikleri ve Sosyal Etkileşim. Akdeniz Üniversitesi Sosyal Bilimler Enstitüsü İletişim Anabilim Dalı yayımlanmamış doktora tezi.

Sığın, İ. (2019). Sosyal medya kullanan gençlerin mahremiyet algısının incelenmesi. Yayımlanmamış yüksek lisans tezi. İstanbul Üniversitesi Sosyal Bilimler Enstitüsü. İstanbul.

Şahin, F. T. (2003). Çocuğun gelişimi ve eğitiminde babanın rolü. Müzeyyen Sevinç (Ed.) Erken Çocuklukta Gelişim ve Eğitimde Yeni Yaklaşımlar içinde(s.459-464). İstanbul: Morpa Kültür.

Türkyılmaz, Z. (2014). 3-6 Yaş grubu çocuğu olan ebeveynlerin mahremiyet eğitimine dair bilgilerinin incelenmesi (Üsküdar örneği). Üsküdar Üniversitesi Sağlık Bilimleri Enstitüsü. İstanbul.

World Association for Sexual Health (WAS). (1999). Declaration of Sexual Rights. 20/02/2020, http://www.worldsexology.org/resources/declaration-of-sexual-rights/.

Yannacopoulos, A. N. (2008). "A risk model for privacy insurance” (Ed. Alessandro Acquisti et al.). Digital Privacy-Theory, Technologies, and Practices (347-360). New York- London: Auerbach.

Yıldırım, A., \& Şimşek, H. (2005). Sosyal bilimlerde nitel araştırma yöntemleri. Ankara: Seçkin Yayınevi.

Yüksel, M. (2003). Modernleşme ve mahremiyet. Kültür ve İletişim, 6 (1), 74-103. 


\title{
Privacy Education in Turkey Based on the Views of School Principals
}

\author{
Erol KOÇOĞLU* \& Yunus Emre AVCI**
}

• Received: 06.07.2021 • Accepted: 31.10 .2021 • Online First: 31.10 .2021

\begin{abstract}
Privacy education, which is more commonly expressed as sexual education today, can be defined as the education that an individual should receive to learn the requirements and responsibilities regarding their gender as a woman or a man. The privacy education demanded by society; may differ according to many variables such as time, cultural background, family, geography. This study aimed to evaluate privacy education in Turkey in line with the opinions of school principals. The study group was determined by a simple random sampling technique and consisted of 40 school principals working in various public schools in Turkey. This study was designed according to the phenomenological approach, one of the qualitative research methods. The research data were analyzed using the content analysis technique, and the researchers created thematic codes. A semistructured interview form prepared by the researchers was used to collect data. Research data were collected from online interviews with school principals through the questions in the interview form. The findings obtained in the study are presented in tables and figures. Considering the findings of the study, it can be said that many remarkable results have been achieved, such as explaining privacy education with the theme of sexual awareness, privacy education in schools is necessary because it provides a safe life opportunity for the individual, and studies on privacy education in schools have increased in recent years to increase individual awareness.
\end{abstract}

Keywords: Privacy education, privacy, bodily awareness, school principal, interview.

\section{Cited:}

Koçoğlu, E., \& Avcı, Y. E. (2022). Privacy education in Turkey based on the views of school principals. Pamukkale University Journal of Education, 54, 385-409.doi:10. 9779.pauefd.963546

\footnotetext{
* Assoc. Prof., Malatya, Turkey, ORCID: 0000-0003-4595-2892,erol.kocoglu@inonu.edu.tr

** Assist. Prof., Siirt, Turkey, ORCID: 0000-0002-1361-1463,yunusavci027@hotmail.com
} 


\section{Introduction}

The family is the most basic unit of all world societies from past to present. For this reason, it can be said that it shows flexibility due to family, geography, culture, climate, sociocultural and economic structure. Depending on this flexibility, it can be said that the impact of a human being, a member of any family, on his life begins before he is born and maintains its influence until the end of his life. The family to which the child is attached with a sense of belonging can shape itself in many ways (Özaslan ve Gültekin Akduman, 2018). Playing an active role in the child's social adaptation prepares them for social life and ensures their integration with social life. It can be said that the sense of ownership, the characteristics of the family, which is the first institution or environment acquired by the child, affects his/her development in many dimensions in the context of the past and the future. These dimensions can be listed as emotional, socio-cultural dimensions. Throughout history, it can be said that the family's upbringing style and attitudes have an important effect on the formation of the individual's personality structure, behaviors and attitudes, since the family has been the primary institution in the comprehensive transfer of the material and moral values of the society in which the individual lives (Jago, Davison, Brockman, Page, Thompson and Fox, 2011). Since the family is effective on the child's cognitive, emotional and psychomotor development, it can be stated that it is effective in the formation of the individual's awareness about privacy (sexuality) education. However, the family is the first place where questions about privacy (sexuality) education, including curiosity and desire to learn, find answers. Therefore, it can be said that the basic principles of privacy education were introduced in the family for the first time.

When the studies on the concept of privacy education, which is the main subject of the study, are examined, it can be said that the concept of sexuality education comes to the fore. Although the concept of sexuality education is generally expressed as the level of awareness of the sexual characteristics of the individual in the world, it can be said that this concept is more than the known definition because sexuality education includes the individual's holistic recognition of his bodily organs and being a role and model in the social sense regarding their functions. From this point of view, this study was carried out in line with the concept of privacy education, which includes the cultural, religious, and moral reflections of sexuality education. Privacy education can be expressed as the education given to children and adolescents to learn about themselves or the characteristics of the opposite sex, to understand and accept their gender roles, and to meet their sexual needs within the 
framework determined by religion, morality, and culture (Diler, 2015; Güneş, 2017). In other words, privacy education is to educate the individual's interests and wishes in a religious, moral, or more comprehensively humane way so that the individual can both protect his own private space and respect the private areas of others. As the definitions indicate, privacy refers to an area that should belong to the individual and be private (Güneş, 2017).

\section{Theoretical Background}

From the past to the present, the individual has struggled with many social, cultural, developmental, and psychological problems during his life. In order to identify these problems, it can be said that the values that will give clues about the characteristics of the developmental period of human beings are adopted, and it is in an effort to determine which of these values are threatened (Mills, 2001; Livberber Göçmen, 2018). Especially in the modern age, the individual's questions such as "what should I do, how should I behave, what kind of person should I be, how should I live this life, and who am I?" He started to question the period he was in with questions such as increased awareness about his life process (Giddens, 2014; Livberber Göçmen, 2018). The fact that an individual learns the answers to these questions by observing the lives of others, especially in today's world, can be considered an indication that a well-founded privacy education is not given to him in the family or the preschool period.

The family, which is one of the important sociological institutions of society, has a decisive influence on the vital preferences of the individual; it can be said that it is effective in shaping physiological, sociological, psychological, economic, and social aspects (Şahin, 2003). This can be expressed as proof of the importance of the family from prenatal development to the end of the individual's life (Jago et al., 2011). Considering the developmental periods of the individual, the family has critical importance. Namely, the formation of the individual's personality and the shaping of his behaviors first occur under the control of the family. It can be said that the individual first establishes a relationship with his family and lays the foundations of his social and emotional development through the experiences he has gained from the family (Özaslan \& Gültekin Akduman, 2018). Thanks to this foundation, the individual can gain the features of the next developmental periods in a more self-confident way. One of these periods is the pre-school period, where the individual gains the most basic skills and habits, realizes the first learning, can transfer himself, can control himself, is aware of his competencies and attaches importance to the competencies 
of others, and privacy education is given (Köksal Akyol, 2015; Özaslan and Gültekin Akduman, 2018). From the perspective of privacy education, the preschool period constitutes a critical period.

With the end of the traditional period and the beginning of modernization, privacy education has gained importance. Because with modernization, it can be said that societies give more importance to sexuality education, which increases the awareness of the individual's sexual body. It can be stated that this importance given to sexuality education prioritizes recognizing the physical characteristics of the individual and fulfilling the responsibilities of these characteristics (Yüksel, 2003). This education has emerged in the international community with the modernization period. This right to education is emphasized in Article 6 of the Declaration of Sexual Rights of the World Association for Sexual Health. In this declaration, it is stated that "every individual has the right to privacy regarding his/her sexuality, sexual identity and sexual behavior without being subjected to any interference." This right includes keeping the subjective content about the person and the concept of privacy confidential (World Association for Sexual Health, 1999). It can be said that this situation is violated in today's world. In particular, it can be stated that the individual should be protected and supported in every sense within the framework of privacy education since social networking sites are used unconsciously and without considering moral rules in the communication process (Litt, 2013), and this situation exceeds the privacy limitations of the individual and puts him under pressure (Yüksel, 2003). It can be said that this siege brings together parents to carry out planned activities, especially in terms of children's use and use of digital platforms (Majedi, Ghazinour, Chinaei and Barker, 2009; Saeri, Ogilvie, La Macchia, Smith and Louis, 2014). These activities can be expressed as practices that make children reliably conscious about privacy or sexuality (Yannacopoulos, 2008). Privacy education, which includes these practices, can be defined as a value education that directly affects the inner world of the child and contributes to the environment where he or she does not experience orientation problems (Güneş, 2015; Özaslan \& Gültekin Akduman, 2018).

Privacy education, which can be defined as a value education, can be stated that in today's world, in any geography of the world, it can be stated that the child, who acquires the competencies of the developmental periods healthily, imposes very important responsibilities on parents and school principals, who have a decisive influence on the education of the child so that he can defend himself against threats from the environment. At 
the beginning of these responsibilities, it can be said that privacy education and the transfer of requirements come first. This education, whose foundations are laid in the family, is transferred in method or technique in all other education levels, especially in the pre-school period, depending on how parents bring the child together with this education (Çakır, 2015). As stated above, preschool can be expressed as the critical period in gaining privacy education. The importance of privacy education and this period in terms of education is expressed in the report on privacy education prepared by the Ministry of Family and Social Policies in Turkey (Eraslan, Ergüt, Uysal, \& Bulut, 2017; Özaslan \& Gültekin Akduman, 2018).

The importance of privacy (sexuality) education can be based on the fact that it considered as a type of education that directly touches the personality and spirit of the child, nourishes both the child and the environment to which the child is connected with a sense of belonging and adds value to this environment. For this reason, it is important to study privacy education by considering it in this study. Considering the importance of privacy education in the report prepared by the Ministry of Family and Social Policies in Turkey, this study aims to determine how school principals perceive "privacy education" and what they think about it. For this purpose, the following research problems were identified in the study:

- According to school principals, what is privacy education?

- According to school principals, what should be the content of privacy education?

- According to school principals, how should privacy education be given?

- According to school principals, what effects do media tools have on privacy education?

\section{Method}

In this study, which was carried out with the qualitative research method, the method part was composed of sub-headings after the ethics committee approval report was received. These sub-headings are detailed in the method section in line with the study subject.

\section{The Research Model}

This study is designed according to the phenomenological approach, one of the qualitative research methods. Qualitative research can be defined as a method that uses many techniques (observation, interview, document analysis, etc.) to obtain research data and express opinions, perceptions, and events related to the research subject inclusively in the existing natural environment. The phenomenological approach, on the other hand, can be 
expressed as studies that aim to investigate the phenomena that are not completely foreign to us and that we cannot fully comprehend (Yıldırım \& Şimşek, 2005). The phenomenological design was preferred to obtain in-depth information and to consult the ideas of school principals, who are responsible for conducting and supervising educational activities in schools and evaluating privacy education, among many other duties.

\section{Measurement Tools Used in the Study}

The data of this research, which was prepared under privacy education, was obtained by the semi-structured interview form technique. Data were obtained by asking the interview form questions prepared by the researchers in accordance with this technique to the participants in the study group. In this technique used to obtain research data, the questions to be asked by the researcher to each of the members of the study group were prepared in advance with the support of field experts. The researcher asked these prepared questions to the members of the study group within a certain plan. In the interviews, it was ensured that the participants, to whom the questions were asked, could go into detail in order to ensure that they did not give the same answers (Altunışık, Çoşkun, Yıldırım, \& Bayraktaroğlu, 2001). For the interview form used in this research, the relevant literature was searched, a semi-structured draft interview form was prepared, and the school principals were interviewed first, and the corrections were made on the questions. Then, the semi-structured interview form was examined by the field experts, and the form was given its final form.

\section{Study Group (Participants)}

The study group of the research consists of 40 school principals working in preschool, primary and secondary schools and high schools located in 7 city centers (Malatya, Siirt, Aydın, Bartın, Konya, Mersin and Sakarya) in Turkey in the 2019-2020 academic year. In Table 1, the personal characteristics of the school principals participating in the research are given. The study group members, who contributed to the research with their opinions, were selected in line with simple random sampling from random sampling methods. Thanks to this sampling, the participants in the study group who contributed to the research with their opinions were determined with the principle of impartiality. In the simple random sampling method, all units in the universe have an equal and independent chance to be selected for the sample. However, random sampling methods are stronger than other sampling methods in providing representation, and the power of the sample to represent the universe is higher (Özen \& Gül, 2007). 
Table 1. School Principal Demographics

\begin{tabular}{|c|c|c|c|c|c|}
\hline Principal & Gende & Education & Profession & Administrativ & $\overline{\text { Age }}$ \\
\hline Principal 1 (Md1) & Male & Undergraduat & 16 and over & $11-16$ & $36-54$ \\
\hline Principal $2(\mathrm{Md} 2)$ & Male & Undergraduat & $6-10$ & $1-5$ & 35 or younger \\
\hline Principal 3 (Md3) & Male & Undergraduat & $1-5$ & $1-5$ & 35 or younger \\
\hline Principal 4 (Md4) & Male & Graduate & $1-5$ & $1-5$ & 35 or younger \\
\hline Principal 5 (Md5) & Male & Undergraduat & $6-10$ & $1-5$ & 35 or younger \\
\hline Principal 6 (Md6) & Male & Undergraduat & $6-10$ & $1-5$ & 35 or younger \\
\hline Principal 7 (Md7) & Male & Undergraduat & $6-10$ & $6-10$ & 35 or younger \\
\hline Principal 8 (Md8) & Male & Undergraduat & $1-5$ & $1-5$ & 35 or younger \\
\hline Principal 9 (Md9) & Male & Undergraduat & $1-5$ & $1-5$ & 35 or younger \\
\hline Principal10 & Male & Undergraduat & $6-10$ & $1-5$ & 35 or younger \\
\hline Principal11 & Female & Graduate & $11-16$ & $6-10$ & $36-54$ \\
\hline Principal12 & Male & Undergraduat & $6-10$ & $1-5$ & 35 or younger \\
\hline Principal13 & Male & Undergraduat & $6-10$ & $1-5$ & 35 or younger \\
\hline Principal14 & Male & Undergraduat & 16 and over & 16 and over & $36-54$ \\
\hline Principal15 & Male & Undergraduat & $11-16$ & $6-10$ & $36-54$ \\
\hline Principal16 & Male & Undergraduat & $1-5$ & $1-5$ & 35 or younger \\
\hline Principal17(Md1 & Male & Undergraduat & $1-5$ & $1-5$ & 35 or younger \\
\hline Principal & Male & Undergraduat & $11-16$ & $6-10$ & $36-54$ \\
\hline Principal & Male & Undergraduat & $6-10$ & $1-5$ & 35 or younger \\
\hline Principal & Male & Undergraduat & $1-5$ & $1-5$ & 35 or younger \\
\hline Principal & Male & Undergraduat & $6-10$ & $1-5$ & $36-54$ \\
\hline Principal & Male & Undergraduat & $6-10$ & $1-5$ & 35 or younger \\
\hline Principal & Male & Undergraduat & $6-10$ & $1-5$ & $36-54$ \\
\hline Principal & Male & Undergraduat & $6-10$ & $1-5$ & $36-54$ \\
\hline Principal & Male & Undergraduat & $1-5$ & $1-5$ & 35 or younger \\
\hline Principal & Female & Undergraduat & $6-10$ & $1-5$ & 35 or younger \\
\hline Principal & Male & Undergraduat & $1-5$ & $1-5$ & $36-54$ \\
\hline Principal & Male & Undergraduat & $1-5$ & $1-5$ & 35 or younger \\
\hline Principal & Female & Undergraduat & $1-5$ & $1-5$ & 35 or younger \\
\hline Principal & Male & Undergraduat & $1-5$ & $1-5$ & $36-54$ \\
\hline Principal & Female & Undergraduat & $1-5$ & $1-5$ & 35 or younger \\
\hline Principal & Male & Undergraduat & $11-16$ & $1-5$ & 35 or younger \\
\hline Principal & Female & Undergraduat & $1-5$ & $1-5$ & $36-54$ \\
\hline Principal & Female & Undergraduat & $1-5$ & $1-5$ & 35 or younger \\
\hline Principal & Male & Undergraduat & $1-5$ & $1-5$ & $36-54$ \\
\hline Principal & Male & Undergraduat & $1-5$ & $1-5$ & $36-54$ \\
\hline Principal & Female & Undergraduat & $11-16$ & $1-5$ & 35 or younger \\
\hline Principal & Female & Undergraduat & $1-5$ & $1-5$ & 35 or younger \\
\hline Principal & Male & Undergraduat & $1-5$ & $1-5$ & $36-54$ \\
\hline Principal & Male & Undergraduat & 16 and over & $6-10$ & 35 or younger \\
\hline
\end{tabular}




\section{Data Collection and Analysis}

Methods to conduct research-oriented interviews by interviewing 50 school principals working in preschool, primary, secondary and high schools in 7 city centers in Turkey (Malatya, Siirt, Aydın, Bartın, Konya, Mersin, and Sakarya) via Google Meet. Discussed. After discussing and understanding the appropriate time for school principals, online oneon-one interviews were held. The answers given during the interview were recorded in the interview forms by the researchers. The answers given by several school principals from these interviews were found insufficient by the researchers and were not included in the study. In the online interviews with the school principals, the data recorded by the researchers were described and interpreted. The "content analysis" process was followed in the analyzes (Yıldırım \& Şimşek, 2005). The data were divided into categories according to their distinctive features, and cause-effect relationships were tried to be examined, and summary information that the reader could easily see was tried to be reached. In the example sentences, the person who thought of the thought was added by shortening it at the end of the sentence. (For example, it is coded at the end of the statements as Director 1= Md1). The personal characteristics of the principals, whose thinking is given as an example, can be viewed in the table under the heading "Working Group" (Table 1). In order to increase the validity of the research, the researchers, while taking the opinions of the school principals on the subject, avoided the questions and behaviors that would direct them and showed an objective approach as if it were a natural part of the interview in the virtual environment. It is very important for the reliability of the research that the members of the study group, who contributed to the research with their opinions, gave similar answers to the questions in the interview form at three-week intervals.

\section{Findings}

\section{The Concept of Privacy}

During the online interviews, the participants were asked to define privacy. The responses of the principals are presented in the form themes in Figure 1. The principals in the study group expressed various perceptions about the definition of privacy (Figure 1). Based on the study findings presented in themes, the school principals mentioned private and sex education concepts about privacy. Reported stated by Sepetçi (2017) and Aydın Avşar (2018), it could be suggested that school principals exhibited an approach suitable for eastern societies by emphasizing privacy and secrecy in the private elements theme. This fact provided 
significant clues about the perceptions of educational administrators about the concept of privacy, which is the foundation of privacy education, also called sex education.

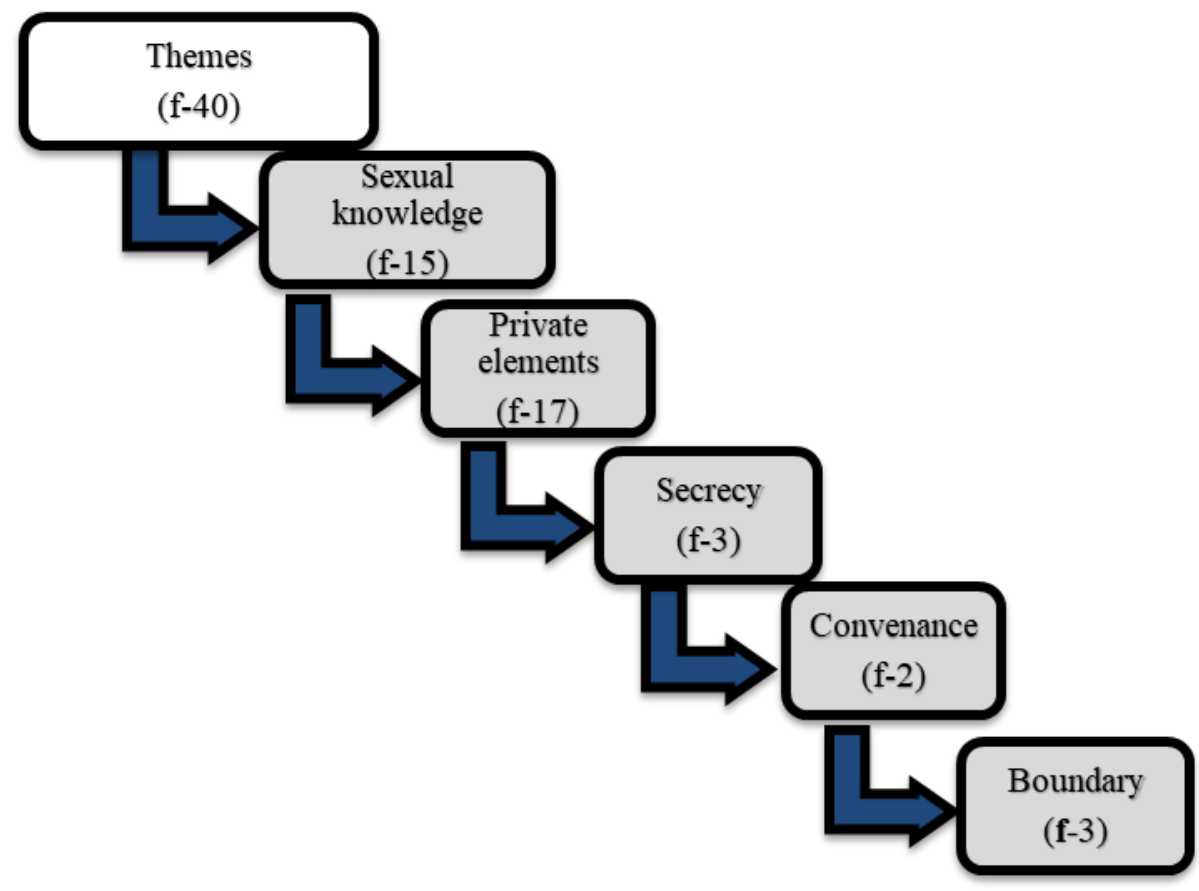

Figure 1. The perceptions of the study group members about the concept of privacy

Since it is not easy to express concepts and facts with a descriptive statement, we tend to express these with other concepts that we consider synonymous or with connotations. The school principals frequently included concepts and facts that they considered similar when describing the concept of privacy. The principals primarily mentioned the concepts of private/personal, knowledge, field, and attributes about the concept of privacy. These concepts were followed by views on learning sexual information, ensuring privacy, and adopting the rules, norms, and boundaries called convenience. The direct quotes of school principals who mentioned sex knowledge and sexuality when defining the concept of privacy are as follows:

"About privacy, I think about sex knowledge. In general, sexuality and knowledge on sexual properties of the body could be included in this concept" (Md4). It is the possession of and protection of information about sex, which is considered private (Md15). Being aware of the private areas of one and others, respecting the privacy of others in social life, protecting one's privacy, and setting healthy boundaries in social relationships are privacy (M18). It is the awareness of one's own and other people's private space, protecting one's own private space in social life and respecting the privacy of others" (Md23). 


\section{The Necessity of Privacy Education}

The responses of the school principles to the second question in the semi-structured interview form, "Do you think privacy education should be instructed at school? Why?" are presented under two themes: "Yes" and "No". Themes and sub-themes, and reasons are presented in Figure 2.

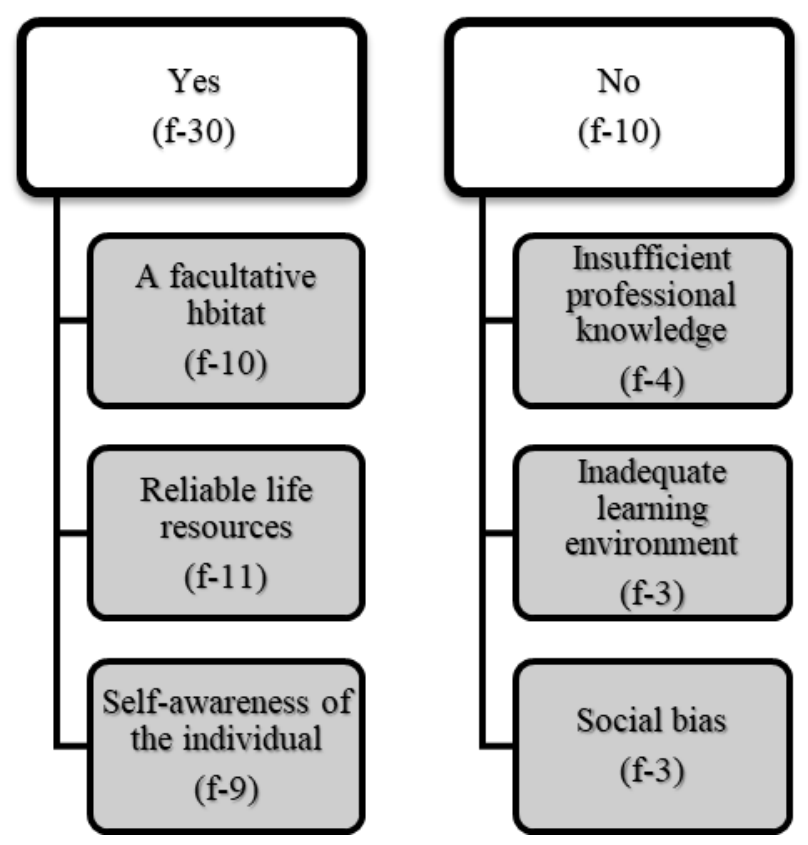

Figure 2. The views of the study group members on the necessity of privacy education at school

As seen in figure 2, it could be suggested that the reasons stated by school principals about the necessity of privacy education at school were significant. Three-quarters of the school principals stated that privacy education should be instructed at school and argued various reasons. On the other hand, a quarter of the principals claimed that privacy education should not be instructed at school, citing the lack of social tolerance/open-mindedness for privacy education, the inadequacy of the learning environment at schools for instruction, and the lack of professional knowledge on privacy education among teachers. The direct quotes of school principals who stated that privacy education should be instructed at school are presented below:

"It is important to provide privacy education at school. Accurate, scientific information could only be instructed at schools. Hearsay leads to bigger problems when inaccurate information is provided to students outside of the school" (Md38). "I find it necessary to instruct privacy education at school. Because privacy education is a broad phenomenon that could not be instructed in a day, it must be 
explained over time. The accuracy of the information the student would learn from his peers or relatives and family could not be guaranteed and may include certain mistakes. However, I consider it more appropriate to provide professional education at school" (Md12).

The direct quotes of school principals who stated that privacy education should not be instructed at school and was not necessary are presented below:

"As an administrator with five years of experience, I think that I should answer your question based on the families and circumstances of the students who attend my school; I do not consider this education necessary because I think that the location of my school and the tolerance of the people are adequate to instruct this education at school" (Md32). "Since this education requires a competency that requires distinct expertise, I think it is not right to provide privacy education at school because the proficiency level of our teachers is not adequate" (Md34).

\section{The Privacy Education Activities Conducted at School}

The findings on the question " Do you conduct privacy education classes/activities at your school? Provide details if you do" are presented in figure 3. The majority of school principals stated that they conducted several privacy education activities in their schools. Twelve principals stated that they did not conduct any privacy education activity at school, and they stated that it was not their responsibility and the approach of the parent-teacher association was negative (Figure 3). Based on the efforts spent by the school principals in the study group, it could be suggested that most efforts centered on sex education and awareness.

The direct quotes on privacy education activities conducted at schools are presented below: "As a primary school principal, I think privacy (sex) education is very important in raising the awareness about the future of the individuals. Thus, based on the developmental attributes of the students who attend the school, we conduct certain programs with the counseling staff on self-recognition techniques" (Md39). "I worked four years as a school administrator, and I think that adequate privacy education is not provided in educational institutions in Turkey. This is due to the parents' perception that privacy education should be provided only due to ethical issues. On the individual level, we try to teach gender equality by inviting experts from universities" (Md23). "Yes, we do conduct activities on privacy education. Since this is a middle school, the counselor instructs the children who transition about the changes they experience or will 
experience since our male counselor instructs the male students, while seminars are organized for female students by a health center nurse" (Md12).

The direct quotes from the statements of the principals who did not conduct privacy education activities at schools are presented below:

"Since we never provided privacy education at my previous schools, we never provided privacy education at the school where I currently work. As a school principal, I think privacy education should be provided by Guidance Research Centers rather than the schools, and they should conduct all required activities" (Md2).

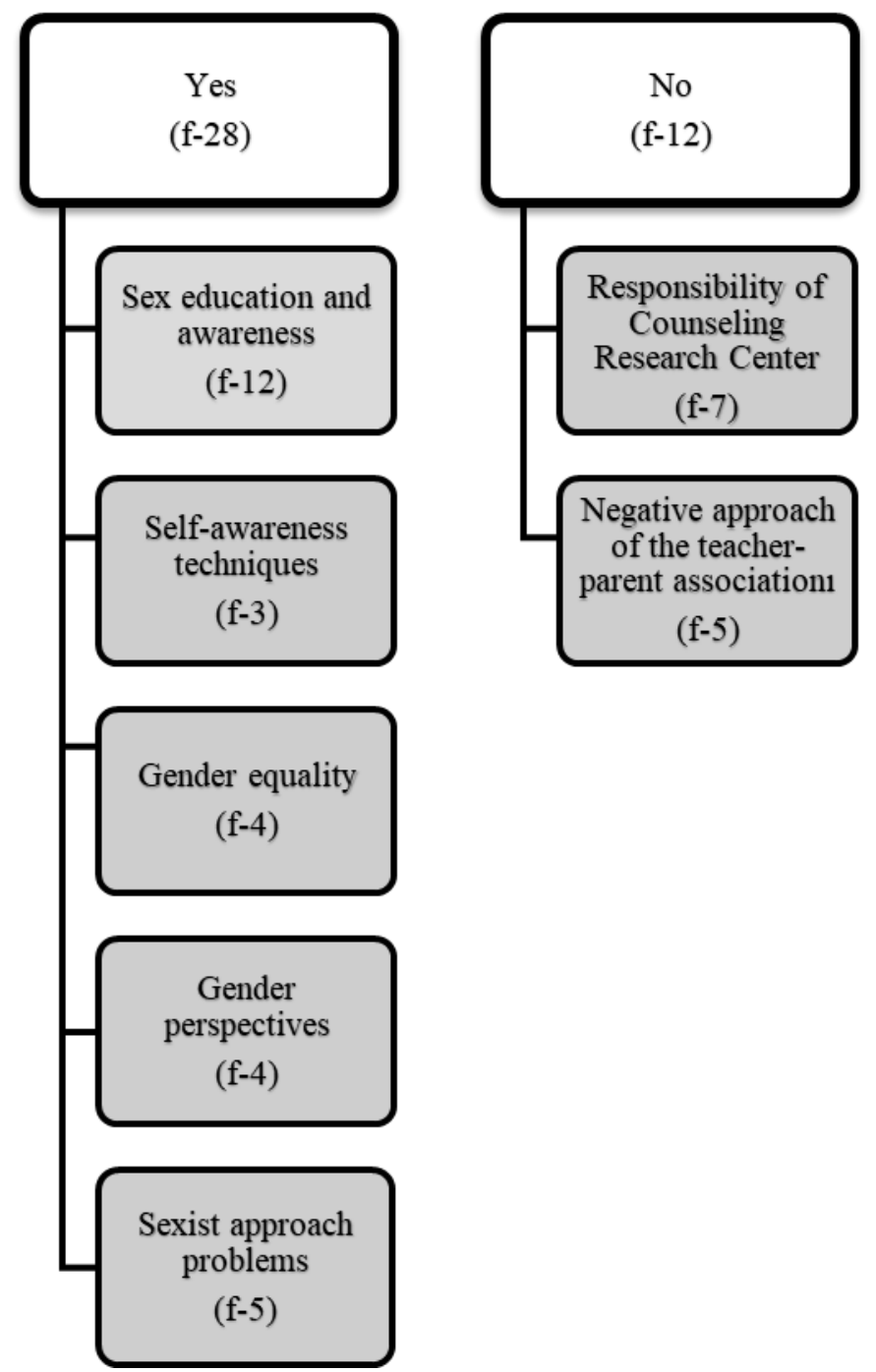

Figure 3. The views of the study group members on privacy education activities at schools 


\section{Privacy Education Content}

School principals provided interesting responses to the question "What should privacy education include?" The school principals mostly mentioned issues associated with sex education and related processes. This might be due to the high level of awareness among the study group members about sex education. It could be suggested that this awareness contributed to principals conducting sex education activities at schools.

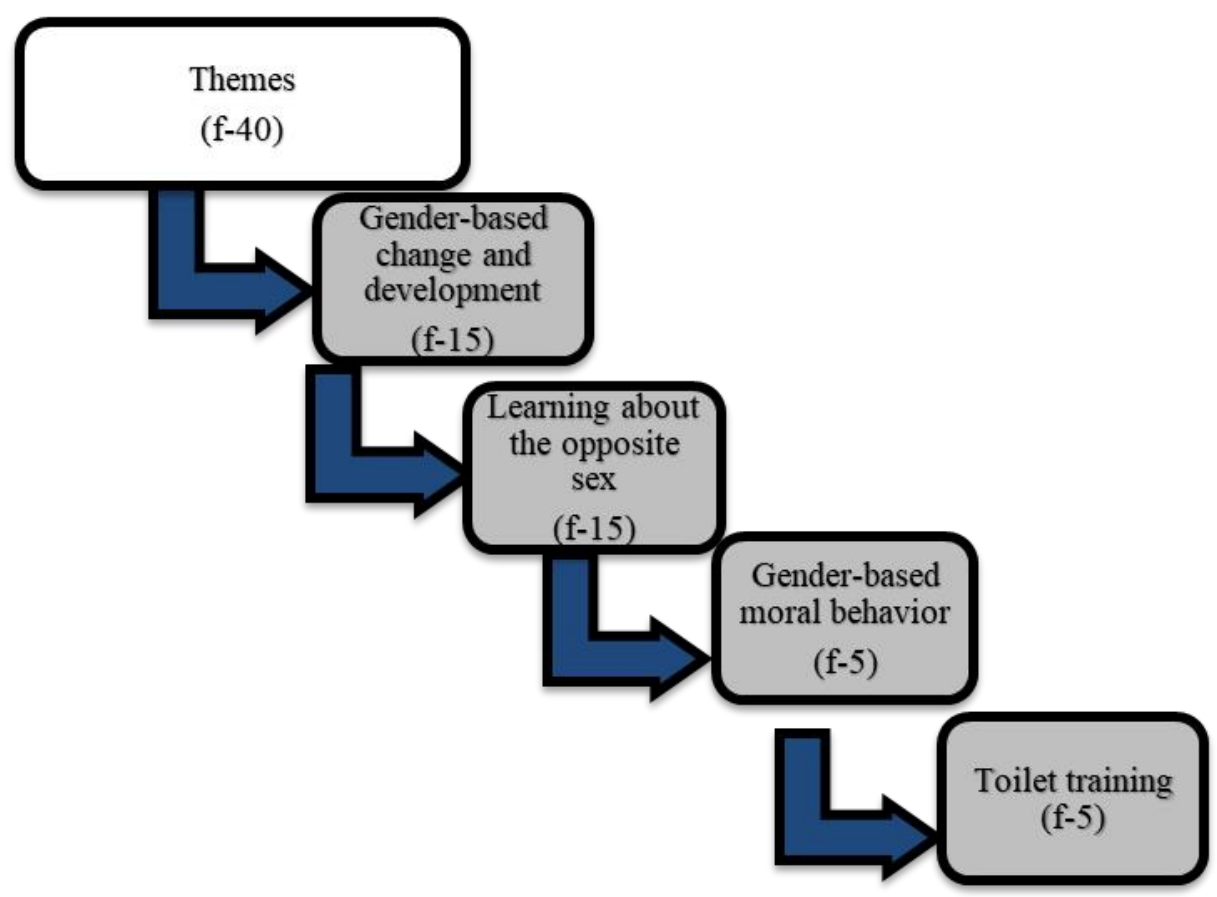

Figure 4. The views of the study group members on privacy education content

The direct quotes of school principals are presented below:

"Most of the concepts that I think about privacy education are similar to sex education. In fact, the gender-based behavior of the individual should not conflict with the regulations of the country of citizenship and the moral rules of the society. Thus, in response to your question, privacy education content should entail the consideration of sexual behavior within ethical limits" (Md1). "In general, privacy education content should include information and physical attributes related to sexuality. For example, adolescence period characteristics, information about the opposite sex, physical information associated with the period, and physical properties can be instructed" (Md10). "I think that issues such as toilet training, personal hygiene and care, knowledge about the body, protection of the body, and determination of proximity and personal space should be addressed in privacy education” (Md13). 


\section{The Instructor of Privacy Education}

The participating school principals were asked, "Who should instruct privacy education at schools? Why?" The analysis findings are presented in the form of themes in figure 5.

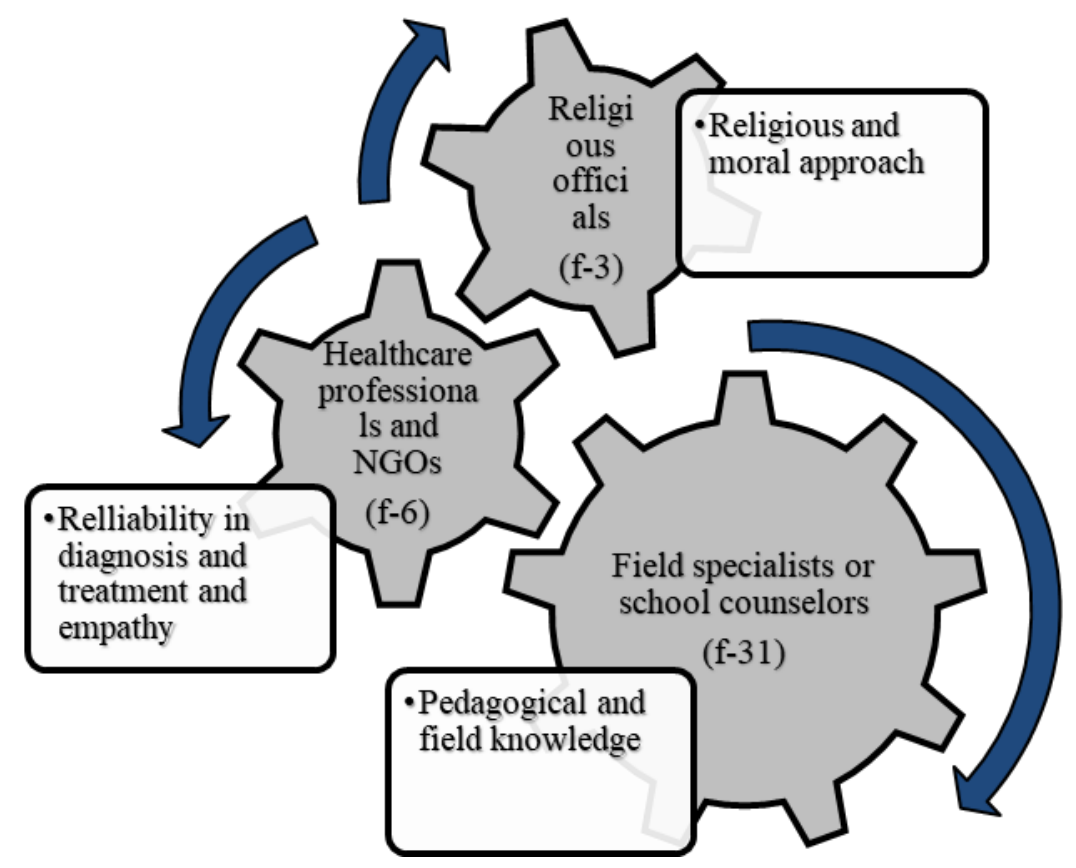

Figure 5. The views of the study group members on who should instruct privacy education

It was determined that the study members formed three groups about the instructor of privacy education (Figure 5). However, all participants emphasized that the instructors should be qualified professionals. The direct quotes of school principals are presented below:

"In my opinion, since professionals should instruct privacy education, it should be instructed by field experts or school counselors who were trained in this field and have a certificate of competence. Because I think these are the members of a profession that could best define the behavior that an individual would exhibit during the development process" (Md44). "I think that professionals should instruct privacy education with high trust levels in the society and parents. In my opinion, these include healthcare professionals who speak and explain with documents and based on evidence. Thus, privacy training should be instructed by healthcare professionals who are experts in this field” (Md7). "Counselors, healthcare professionals, and muftis could instruct it. The pedagogical experts in this field are school counselors, healthcare professionals in health and physical care, and muftis who know the ethical aspects of privacy. Education should be instructed by a professional team that would include the staff mentioned above on a common platform" (Md3). 


\section{The Impact of Media on Privacy Education}

It could be observed in figure 6 that the study group members expressed interesting responses to the research question, " Do media have an adverse effect on privacy education? Why?" Almost all principals (f-35) stated that media had adverse effects on privacy education, and they justified this argument with various themes (Figure 6). It was determined that 5 principals stated that media did not negatively impact privacy education since children use media tools under parental supervision and the media messages are encrypted (Figure 6).

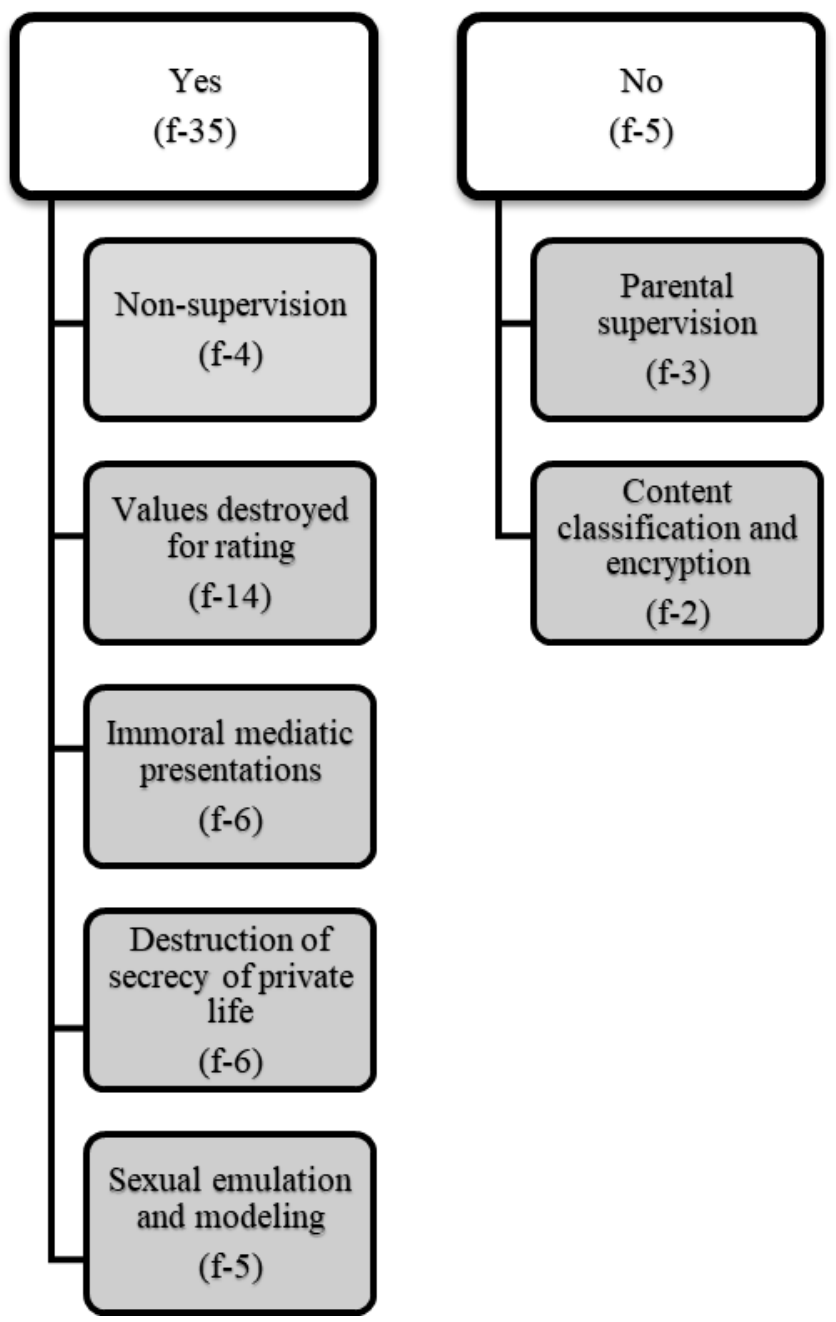

Figure 6. The views of the study group members on the impact of media on privacy education

The sample views of school principals are presented below:

"As a school principal and father, I think this is a very important question. Before the privacy education, we can observe several shows that obliterate the term privacy (hidden, secret, sin, haram) in the media. This, unfortunately eliminates the privacy 
perception of children and young adults. A problem on privacy that a 20-year-old young man would ashamedly ask in the 1980s could be answered by a 7-8 years old child based on the information acquired on the media. This renders privacy education worthless for children and young adults. Well, if you ask what we should do, we should supervise our children when using media up to a certain age" (Md21). "It should not be forgotten that no economic gain is more important than our children and our youth because they are future teachers, doctors, architects, engineers etc., who will build the tomorrow. If we do not want to destroy our future, we must raise a generation with a strong sense of privacy. Thus, rating-based media shows that promote non-privacy allowed for the sake of economic gain should never be allowed" (Md11). I think it has. Because even for advertising purposes, sexually explicit topics appear on phones, tablets, and computers and inevitably attract adolescents. Privacy is destroyed by such content that knows no boundaries in privacy and is sexually effective" (Md12).

\section{Discussion and Conclusion}

The purpose of this research is to evaluate privacy education from the perspectives of school principals. In the qualitative research design with a phenomenological approach, data were obtained by conducting online interviews with 40 school principals working in public schools, and the data were analyzed by content analysis technique and presented. Research results are given in order.

The part that stands out in the privacy definitions of school principals is personal; information, domain, characteristics, and sexual information. Different examples that can be explained with privacy, etiquette, and boundaries are also mentioned in the definitions of privacy. Privacy is as old as human history, but there are differences in periodical and social definitions and what is private and should be protected (Lukács, 2016). As a matter of fact, although bodily privacy is one of our most valuable rights in our legal and common moral regulations, the level of having the qualifications of privacy education has not reached a higher status (More, 2003). The general result that comes to the fore in the study is that the concept of privacy is expressed with the concept of sexuality. When we look at the studies conducted in line with this result, Çalışkan (2019) associated privacy with sexuality and physical characteristics more than teacher statements in his study sample of preschool teachers. In Çakır's (2015) research, parents' definitions of privacy have been reached in line with the concepts and facts of "confidentiality, inviolability, private space", similar to our research. Again, Duran (2018), in his theoretical work, touched upon creating a special 
space for children, setting boundaries and sexual issues within the scope of the principles of privacy education. Hekimoğlu (2019) examined privacy under the dimensions of "personal privacy, spatial privacy and information privacy".

Regarding the necessity and reason of privacy education, most school principals expressed the necessity of providing privacy education in schools by stating various reasons. The principals, who did not consider it necessary to provide privacy education, presented some shortcomings/deficiencies arising from the teacher, school or society as reasons. Therefore, they argued that all principals considered privacy education necessary in schools but provided appropriate conditions as a justification. The two main reasons stated by school principals regarding the necessity of privacy education are to ensure that students are fed from reliable sources on life-related issues and to protect students from negativities by raising awareness through this education. Similarly, in the research conducted by Çakır (2015) and Türkyılmaz (2019) on parents, all of the parents considered privacy education necessary. Privacy education, which should be effectively taught in the preschool period, is considered important by preschool teachers for different reasons (Çalışkan, 2019). As a matter of fact, Duran (2018), based on the results of his research, states that privacy education should be given to all segments of society, especially students, to create a healthy society.

Regarding the issue of whether any work has been done on privacy education in schools, the majority of the principals stated that some studies had been carried out on gender and sexuality, especially within the scope of guidance service activities. A few of the principals stated that there was no work in their school. While all of the principals find privacy education necessary if appropriate conditions exist, the fact that a few principals do not carry out any activities in their schools contradicts their ideas. The fact that these principals do not do any work even though they see privacy education activities as necessary may mean that they are indifferent to different reasons. The fact that school principals remain passive in an area they deem necessary within the scope of carrying out activities in the field of education, which is an important function, may indicate some problems in practice.

Regarding the content of privacy education, school principals mostly addressed issues related to gender education and its processes. This may be due to the high level of awareness of the study group members regarding gender education. Çalışkan (2019) also stated in his research, regarding the aims of privacy education, touched upon the issue of ensuring the child's self-protection and teaching private areas, and emphasized privacy and 
sexuality in privacy education. Toilet training, expressed by only a few principals, is one of the important processes that includes many skills that should be gained in the preschool period. Privacy education is an important education that includes sexual information but starts long before adolescence when sexual development is intense and should be given to the 0-6 age group, where most personality development is formed (Duran, 2018). Toilet training also includes the elements of privacy, and not changing the baby's diaper in front of others before this period is one of the behaviors that should be done to make privacy feel and grasp. From this point of view, privacy education should be handled more comprehensively. As a matter of fact, Celikoglu (2007), in his research on university students, addressed privacy in 8 dimensions according to participant statements and discussed it more comprehensively in different ways such as "the privacy of the body, the privacy of the home, the privacy of the family, the privacy in interpersonal relations, sexuality and the privacy of the word. Baysal Berkup (2015), privacy; body privacy, home privacy, male-female relations privacy, and religion and political opinion privacy in 4 subdimensions. Çakır (2015), in his study investigating the role of religious education on privacy education in children, differed from our research on issues related to parents' privacy education, such as "not entering bedrooms without permission", "dress, veiling" "wifehusband relations" "conscious use of the internet and TV". They also touched on different issues such as. " This difference may be because, unlike the privacy education in schools, research is conducted in the sample of parents starting from family life. She underlines that since most parents accept it that privacy education should start at the age of 4 and before, privacy education should also be given during periods when sexuality is not yet grasped.

Regarding who should provide privacy education in schools, all school principals stated that experts and experienced people should give privacy education. Referring to people from different people and institutions who can provide this training, the main demand of the principals is that they have expertise in this subject. Similarly, in his study, Çalışkan (2019) determined that privacy education should be given by families, teachers, and experts according to all preschool teachers. As experts on devices provided by the school and student privacy, it is recommended that teachers integrate digital literacy and privacy education into their existing curriculum in the program they implement to prevent spying (Electronic Frontier Foundation, 2017).

Regarding the effect of technology tools on privacy education, almost all principals stated that today's technology tools negatively affect privacy education. Looking at the statements of the principal, it has been determined that technology tools generally have some 
negative effects on privacy in terms of the content they offer. Family control was deemed necessary to turn this effect in a positive direction, and it was emphasized that any content transmitted through social media and digital technology tools, particularly, is privacyabrasive. Especially for young people, this can have alarming consequences. Since all kinds of information circulate uncontrollably on virtual platforms, it can lead to privacy violations and transformations in individuals' perceptions of privacy (Korkmaz, 2012; Karagülle, 2015; Hacıbekiroğlu, 2019). Sengupta and Chaudhuri (2011) emphasize the importance of parents' interaction with their children by revealing that young people who use their computers secretly from their parents are more exposed to bullying in virtual environments in their study on young people aged 12-17. While privacy in social media can be expressed as the right to disclose personal data, it has been common for young people to have posts that would exceed the limits of privacy by themselves or others. Especially young people between the ages of 15-30 use social networks intensively and display their daily lives on social networking sites such as Instagram (Sı̆̆ın, 2019). Because, in the age of internet usage, not only has the traditional form of communication been completely transformed, but people have become able to share the most intimate moments of their lives (or others) almost without any limits (it is enough to consider the extreme popularity of social media) (Lukács, 2016). Social networks, which have become widespread with the acceleration of the digitalization process and the development of new technologies, have caused the perception of privacy and its violation to increase (Hekimoğlu, 2019). The tools and equipment used for communication have removed borders and walls and made each phenomenon visible and demonstrable. On this occasion, technological developments, which were initially regarded as a new invention and an enjoyable tool, have turned into mechanisms that threaten society over time (Lemke, 2014). As a matter of fact, according to Digital's 2020 Global Overview report, 59\% of the world's population (4.54 billion) will be global internet users in 2020, and $45 \%$ reported that they are using social media. The report states that $49 \%$ of the world's population is an active social media user (wearesocial.com). Studies reveal that young people are very active on social media, sharing large amounts of personal information online (Culver \& Grizzle, 2017). It has been revealed that social media addiction also increases in direct proportion to rejuvenation (Kaya, 2019). According to Sengupta and Chaudhuri's (2011) research on young people aged 12-17, participants stated that uploading photos on social networks that all users can access is the key to revealing personal information, visiting online chat rooms, unwanted foreign contacts, or online bullying. They found that girls, in particular, are more vulnerable to online harassment. In a 
study conducted with secondary school students, it was revealed that $24 \%$ of the students were involved in cyberbullying in social networks, boys were more likely to engage in criminal behavior in these environments than girls and were more likely to join harmful groups (Baştürk-Akca, Sayımer, \& Ergül, 2015). Elem Yıldırım (2017) revealed in her research that children are an important risk group for violations of privacy on the Internet. The way to eliminate the harm that mass media can cause is through the awareness of privacy. Those who need to be sensitive in this regard are primarily the person himself and his family (Duran, 2018). In this medium where it is very difficult to provide direct control, the most important measure is to create and protect one's privacy area (Çekiç, 2019). However, since children's self-control is difficult at an early age, families have great responsibilities. It can be said that this situation requires parents to carry out planned activities in terms of children's use and use of digital platforms (Majedi, Ghazinour, Chinaei and Barker, 2009; Saeri, Ogilvie, La Macchia, Smith and Louis, 2014). Based on the results obtained in this research;

$\checkmark$ Authorized institutions should create visual content related to the content of privacy education, and these should be displayed in schools in a remarkable way,

$\checkmark$ Necessary training should be given to everyone (parents, school principals, teachers, etc.) who have an impact on the development of the individual regarding the importance of privacy education,

$\checkmark$ Within the scope of privacy education, the purpose and way of using the media tools of the individual should be controlled by the parents,

$\checkmark$ In order to increase the number of specialist teachers with qualifications related to privacy education, suggestions can be made that this education should be given to prospective teachers at the undergraduate level within the scope of teaching profession knowledge courses. 
Ethical Approval: This research was conducted with the permission obtained by the ethics committee of İönü University, Social and Human Sciences Scientific Research and Publication Ethics Committee with a decision no 2021/13-20 dated 30.06.2021

Conflict Interest: There is no conflict of interest to be declared by the authors.

Authors' Contributions: The first author created the theoretical framework, data analysis, findings, conclusion, and discussion. The second author contributed to creating the theoretical framework, findings, conclusion and discussion, and recommendations.

\section{References}

Altunışık, R., Coşkun, R., Yıldırım, E., \& Bayraktaroğlu, S. (2001). Sosyal Bilimlerde Araştırma Yöntemleri. Sakarya: Sakarya Kitabevi.

Aydın Avşar, S.(2018). Anne-baba ve ergen çocukların mahremiyet algısındaki farklılıkların sosyal medya üzerinden okunması. İstanbul Sabahattin Zaim Üniversitesi Sosyal Bilimler Enstitüsü, Yayımlanmamış Yüksek Lisans Tezi.

Baştürk-Akca, E., Sayımer, İ., \& Ergül, S. (2015). Social media use and cyberbullying experiences of secondary school students: The case of Ankara. Global Media Journal: Turkish Edition. 5(10), 71-86.

Baysal Berkup, S. (2015). Sosyal ağlarda bireysel mahremiyet paylaşımı: $x$ ve y kuşakları arasında karşılaştırmalı bir analiz. Yayımlanmamış doktora tezi. Ege Üniversitesi Sosyal Bilimler Enstitüsü. İzmir.

Culver, S. H., \& Grizzle, A. (2017). Survey on privacy in media and information literacy with youth perspectives. Paris: UNESCO Publishing.

Çakır, S. (2015). 4-6 yaş aralı̆̆ındaki çocuklara mahremiyet eğitimi verilmesinde din eğitiminin rolü (Sivas Örneği). Yayımlanmamış yüksek lisans tezi. Cumhuriyet Üniversitesi Sosyal Bilimler Enstitüsü. Sivas.

Çalışkan, H. (2019). Okul öncesi dönemde çalışan öğretmenlerin mahremiyet eğitimi konusunda bilgi düzeylerinin belirlenmesi. Yayımlanmamış yüksek lisans tezi. Necmettin Erbakan Üniversitesi Eğitim Bilimleri Enstitüsü. Konya. 
Çekiç, S. (2019). İslam hukukunda mahremiyet ve sosyal medya. Yayımlanmamış yüksek lisans tezi. Çanakkale Onsekiz Mart Üniversitesi Sosyal Bilimler Enstitüsü. Çanakkale.

Çelikoğlu, N. (2007). Türkiye'de üniversite gençliğinde mahremiyetin dönüşümü. Yayımlanmamış yüksek lisans tezi. Marmara Üniversitesi Sosyal Bilimler Enstitüsü.

Diler, R. (2015). "Mahremiyet Eğitimi ve Önemi”, Erişim: 01.04.2020, http://earsiv.gop.edu.tr/xmlui/bitstream/handle/123456789/776/ramazan_diler.pdf?se quence $=1$ İstanbul.

Duran, H. E. (2018). Değerler Eğitimi Bağlamında Mahremiyet Eğitimi. Yayımlanmamış Yüksek Lisans Tezi. Ondokuz Mayıs Üniversitesi. Sosyal Bilimler Enstitüsü. Samsun.

Elektronic Frontier Foundation, (2017). Öğrenci casusluğu, okul tarafından verilen cihazlar ve öğrenci gizliliği. https://www.eff.org/tr/node/95598 Erişim tarihi: 28.11.2020.

Elem Yıldırım, F. (2017). Medya psikolojisi bağlamında internet kullanıcıllğg ile oluşan endişeler: mahremiyet endişesi. Yayımlanmamış Doktora Tezi. Marmara Üniversitesi Sosyal Bilimler Enstitüsü. İstanbul.

Eraslan, E., Ergüt İ.K., Uysal, T., \& Bulut, G. (2017). Mahremiyet eğitimi çalıştayı sonuç raporu. Ercüment Erbay (Ed.) Yayın No: 06 Ankara: Aile ve Sosyal Politikalar Bakanlığı. https://cocukhizmetleri.aile.gov.tr Erişim tarihi: 20.12.2020.

Giddens, A. (2014). Modernite ve bireysel kimlik-geç modern çağda benlik ve toplum. İstanbul: Say.

Güneş, A. (2015). Nezaket ve zerafet için mahremiyet eğitimi. İstanbul: Timaş yayınları.

Hacıbekiroğlu, M. (2019). Sosyal Medya Kullanımına Bağlı Değişen Mahremiyet Algısı ve Dindarlkk Illişkisi. Yayımlanmamış yüksek lisan tezi. Necmettin Erbakan Üniversitesi Sosyal Bilimler Enstitüsü. Konya.

Hekimoğlu, H. (2019). Sosyal ağlarda mahremiyetin dönüşümü: instagram örneği. Yayımlanmamış yüksek lisans tezi. Erciyes Üniversitesi Sosyal Bilimler Enstitüsü. Kayseri.

Jago, R., Davison, K. K., Brockman, R., Page, S. A., Thompson, L. J., \& Fox, R. K. (2011). Parenting styles, parenting practices, and physical activity in 10-to 11- Year Olds. Preventive Medicine, (52), 44-47. 
Karagülle, A. E. (2015). Günümüzde değişen mahremiyet algısının sosyal ă̆lar bağlamında incelenmesi. Yayınlanmamış yüksek lisans tezi. İstanbul Ticaret Üniversitesi Sosyal Bilimler Enstitüsü. İstanbul.

Kaya, A. (2019). Üniversite Öğrencilerinde Sosyal Medya Kullanımı İle Mahremiyet Algısı Arasındaki İlişkinin İncelenmesi. Yayımlanmamış yüksek lisans tezi. Üsküdar Üniversitesi Sosyal Bilimler Enstitüsü. İstanbul.

Korkmaz, İ. (2012). Facebook ve mahremiyet: görmek ve gözetle(n)mek. "facebook and privacy: see and watch/being watched". Yalova Sosyal Bilimler Dergisi.

Köksal Akyol, A. (2015). Okul öncesi eğitimin amaçları ve ilkeleri. Aysel Köksal Akyol (Ed.). Okul Öncesi Eğitim Programları. Her Yönüyle Okul Öncesi Eğitim-7 içinde. (s.169-176). Ankara: Hedef yayınları.

Lemke, T. (2014). Biyopolitika. (Çev.) U. Özmakas, İstanbul: İletişim Yayınları.

Litt, E. (2013). Understanding social network site users' privacy tool use. Computers in Human Behavior, 29, 1649-1656.

Livberber Göçmen, T.(2018). Toplumsal yaşamda bireylerin mahremiyet yönelimleri: Sosyal ăg kullanıcıları üzerine bir saha araştırması. Konya Selçuk Üniversitesi Sosyal Bilimler Enstitüsü Yayımlanmamış Doktora Tezi.

Lukács, A. (2016). What is Privacy? The History and Definition of Privacy. In: Keresztes, Gábor (ed.):Tavaszi Szél 2016 Tanulmánykötet I, Budapest, 15- April. Budapest: Doktoranduszok Országos Szövetsége, pp. 256-265. Available from: https://www.semanticscholar.org/paper/What-is-Privacy-The-History-andDefinition-of-Adrienn/430bfacbabb89c0033b6dcceddc18ba9bbc02c5f [Accessed 30 December 2020].

Majedi, M., Ghazinour, K., Chinaei, A., \& Barker, K. (2009) SQL privacy model for social networks. In the Proceedings of the IEEE International Conference on Advances in Social Network Analysis and Mining (ASONAM). Greece. 2 pages.

Mills, C. W. (2001). “Sosyolojik imgelem” . (Ed. Uğur Dolgun). Sosyo-ekonomik perspektif (s. 79-107). Bursa: Asa.

More, A. D. (2003). Prıvacy: 1ts meanıng and value. American Philosophical Quarterly. 40 (3), 124-168.

Özaslan, H., \& Gültekin Akduman, G.(2020). Examining the views of families on privacy education. SETSCI Conference Indexing System, 3 (2018), 1363-1 369. 
Özen, Y. \& Gül, A. (2007). Sosyal ve eğitim bilimleri araştırmalarında evren-örneklem sorunu. Kazım Karabekir ĕgitim Fakültesi Dergisi, 15, 394-422.

Saeri, A. K., Ogilvie, C., La Macchia, S.T., Smith, J. R., \& Louis, W. R. (2014). Predicting Facebook users' online privacy protection: Risk, trust, norm focus theory, and the theory of planned behavior. The Journal of Social Psychology, 154(4), 352-369.

Sengupta, A., \& Chaudhuri, A. (2011). Are social networking sites a source of online harassment for teens? evidence from survey data. Children and Youth Services Review. 33(2), 284-290.

Sepetci, T. (2017). Dijital Oyunlar, Dijital Oyuncular: Karşı Hegemonya Pratikleri ve Sosyal Etkileşim. Akdeniz Üniversitesi Sosyal Bilimler Enstitüsü İletişim Anabilim Dalı yayımlanmamış doktora tezi.

Sığın, İ. (2019). Sosyal medya kullanan gençlerin mahremiyet algısının incelenmesi. Yayımlanmamış yüksek lisans tezi. İstanbul Üniversitesi Sosyal Bilimler Enstitüsü. İstanbul.

Şahin, F. T. (2003). Çocuğun gelişimi ve eğitiminde babanın rolü. Müzeyyen Sevinç (Ed.) Erken Çocuklukta Gelişim ve Eğitimde Yeni Yaklaşımlar içinde(s.459-464). İstanbul: Morpa Kültür.

Türkyılmaz, Z. (2014). 3-6 Yaş grubu çocuğu olan ebeveynlerin mahremiyet eğitimine dair bilgilerinin incelenmesi (Üsküdar örneği). Üsküdar Üniversitesi Sağlık Bilimleri Enstitüsü. İstanbul.

World Association for Sexual Health (WAS). (1999). Declaration of Sexual Rights. 20/02/2020, http://www.worldsexology.org/resources/declaration-of-sexual-rights/.

Yannacopoulos, A. N. (2008). “A risk model for privacy insurance” (Ed. Alessandro Acquisti et al.). Digital Privacy-Theory, Technologies, and Practices (347-360). New York- London: Auerbach.

Yıldırım, A., \& Şimşek, H. (2005). Sosyal bilimlerde nitel araştırma yöntemleri. Ankara: Seçkin Yayınevi.

Yüksel, M. (2003). Modernleşme ve mahremiyet. Kültür ve İletişim, 6 (1), 74-103. 